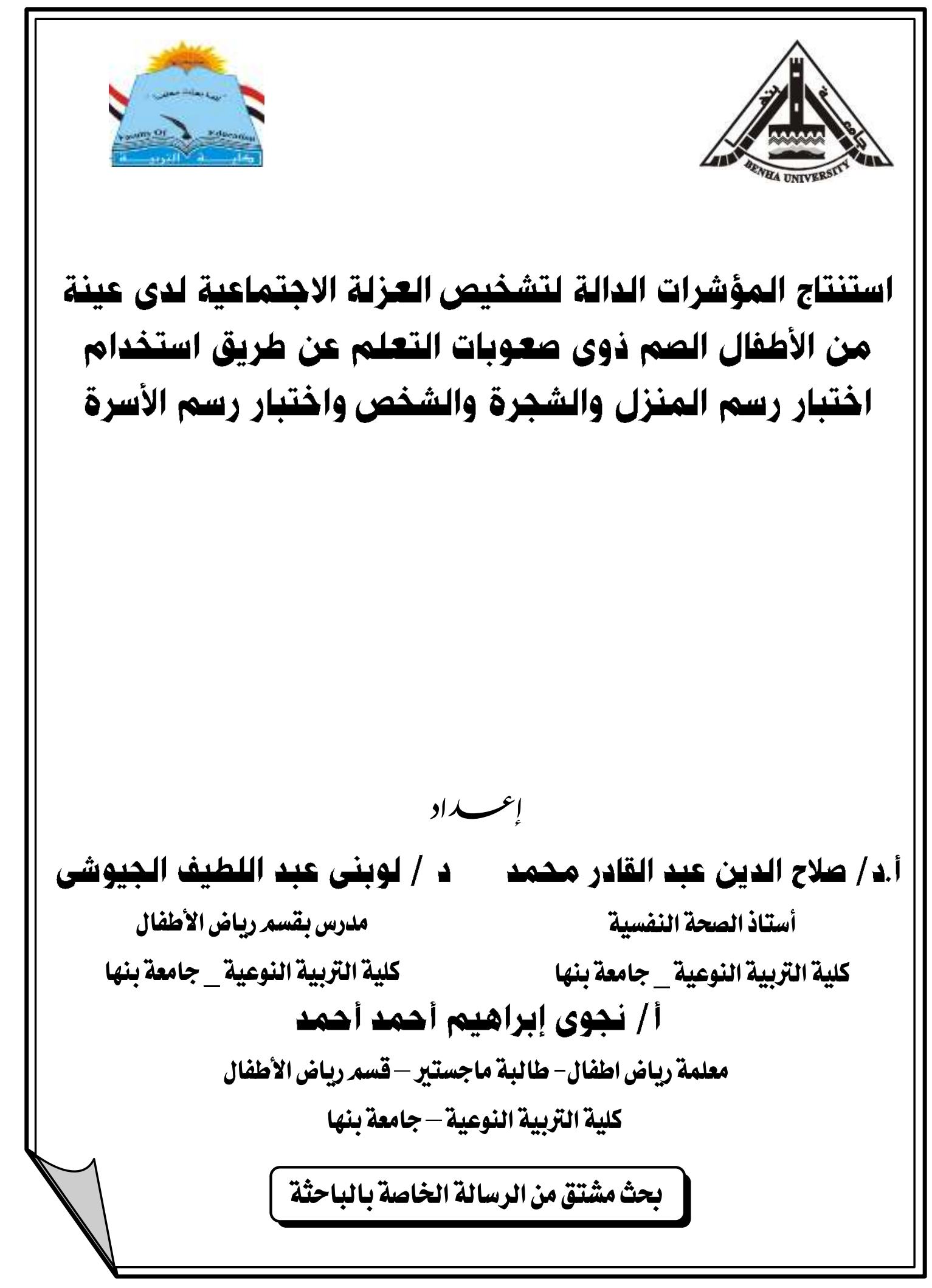


استنتاج المؤشرات الدالة لتشفيص العزلة الاجتماعية لدى عينة من الأطفال

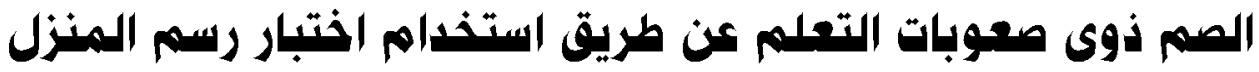
والشجرة والشخص واختبار رسم الأسرة

! إن

أ.د / صلاح الدين عبد القادر محمد د / لوبنى عبد اللطيف البيوشى ملدرس بقسم رياض الأطفال أستاذ الصحة النفسية

كلية التربية النوعية_جامعة بنها كلية التربية النوعية_جامعة بنها

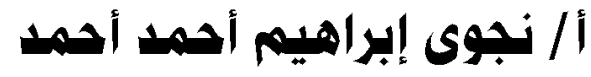

طالبة ماجستير - قسم رياض الأطفال

كلية التربية النوعية - جامعة بنها

\section{ملخـم البدث}

هدف البحث إلى التعرف على المؤشـرات الدالـة لتشـخيص العزلـة الاجتماعيـة لـى

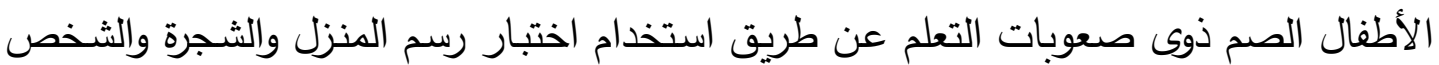
واختبار رسم الأسرة وكانت العينة (؟) من الأطفال الصم ذوى صعوبات التعلم، وتم استخدام

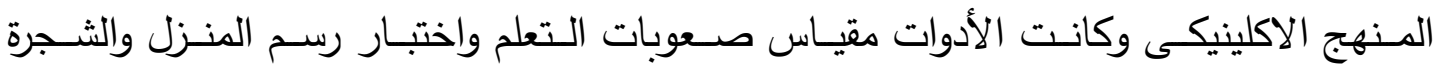
والثخص واختبار رسم الأسرة وبعض الرسوم الحرة مثل (خطر على بالك- رسم حدث هام)

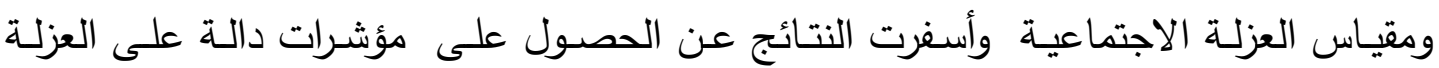
الاجتماعية لدى الطفل الأصم ذوى صعوبات التعلم. 
تعد رسوم الأطفال شكلا من أشكال التواصل، فهي بمثابة رسائل موجهة إلى الأجرين، ووعاء للفكر والمشاعر شأنها في ذلك شأن الكلمات، لاسيما أن اللغة اللفظية بالنسبة للطفل،

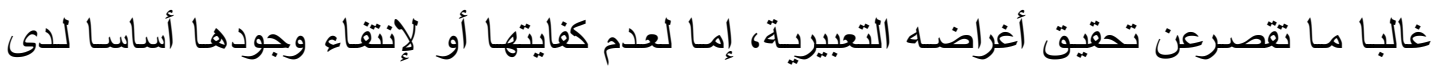
بعض الأطفـال غيرالعـاديين، وهـى تعبيـر صـادق عـن اسـتعدادات الطفل، وحالتـه المزاجيـة

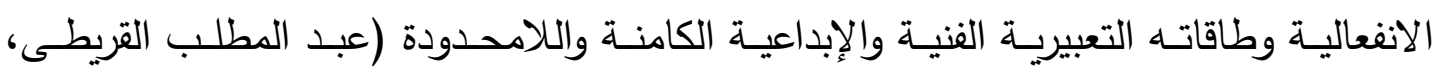
(1)990:0

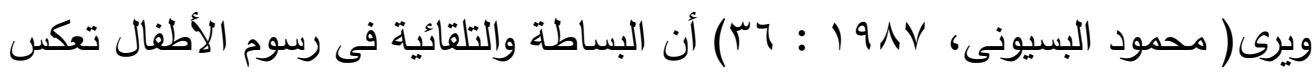
قدرا كبيرا من الحقائق والدلالات التى تضيف الكثير لفهم سيكولوجية الطفل وارتقائه وتوافقه

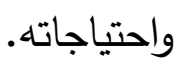

فرسوم الأطفال تعبير صـادق عن رغبات الطفل وحاجاتة، ووسيلة لتسجيل حاضـره وتطلعاته المستقبلية، وتجسيد لمخاوفه وصراعاته ومفهومسه عن ذاته، وهى مرآة تعكس قيمـة واتجاهاته إزاء مختلف الأشياء والمواقف. وبقدر بساطة وتلقائية رسوم الأطفال بقدر خصوبتها وثرائها، ويجد الباحث الثـغوف فيها معينـا لا ينضب من الحقائق والدلالات التى تضيف الكثير لفهمنا لسيكولوجية الطفل،

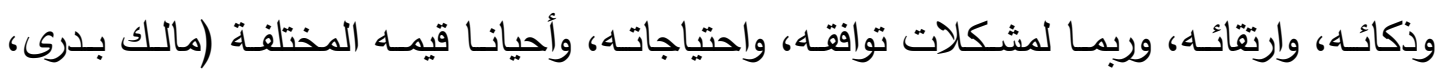

ويشير (عادل خضر، 1991 : .ء ) أن لغة الكلام لاى الصم بها من القصور ما يجعل تواصلنا معهم ضعيفاً فى أضيق الحدود ولابد من مدخل أخر لأقامة الحوار وتحقيق التواصل معهم من خلال لغة بديله، يفصح من خلالها الطفل الأصم باسمى التعبيرات البلاغية التى تتبع من اعماقه ومشاعره الاُّهى وهى لغة الرسم (رسوم الأطفال)

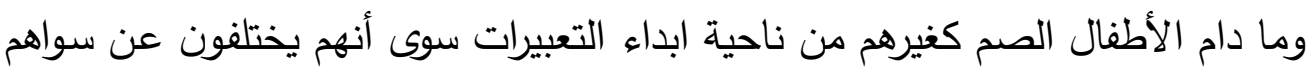

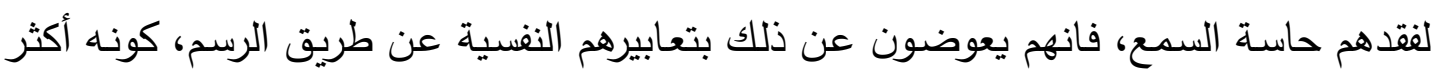

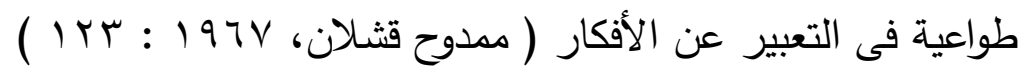


ويذكر لندنرى وديفيد( 146 : David,1992, Lindray ) أن الإعاقة السمعية لها

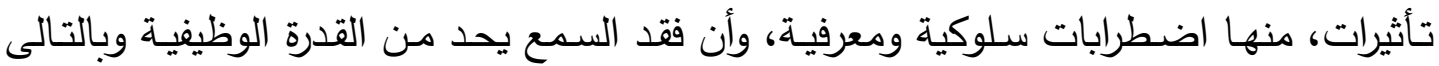
ت تؤدى إلى العزلة الاجتماعية

اتفقت معظم الأدبيات النفسية على أن التثخيص هو أتخاذ قرار بخصوص تحديد

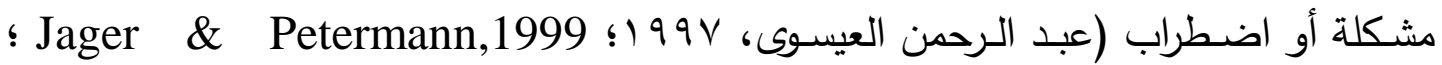

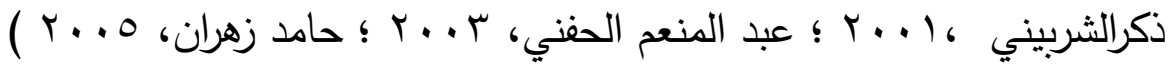
ويتوقف هذا القرار على وسـائل جمـع المعلومـات مـن الحالـة عن موضـوع معاناتـهـ

ويشير عبد الرحمن العيسوى (9971) إلى أن الوسائل الثائعة فى التثخيص ( المقابلة - الملاحظة - الاختبارات النفسية ) إلا أن هناك بعض الملاحظات التى أسهـت فى تفكير الباحثة فى موضوع الدراسة منها ملاحظة عبد الرحمن العيسوى (99V (1) والتى يورد فيها "هناك فرق كبير بين تشخيص وعلاج الأطفال وبين تشخيص وعلاج الكبار فنحن نجد أن قدرة الطفل على الضبط والتحكم فى بيئتة محدودة وأعتمادة على الكبار كبير وتأثيرهم علية ملحوظ ـ وكم

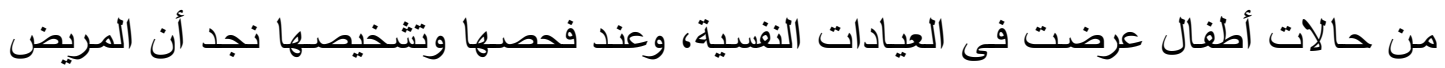
ليس هو الطفل ولكنة أحد الوالدين أو كلاهها، أى أن مرض الطفل يعتبر عرضـا لمرض وض أحد

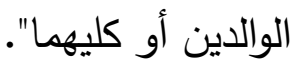

ويضيف عبد الرحمن العيسوى (199V ) أن عملية التشخيص والتصنيف أمرا صعبا

بالنسبة للكبار ولذلك فهى أكثر صعوبة بالنسبة لتثخيص حالات الأطفال وكذلك يشير ( حامد

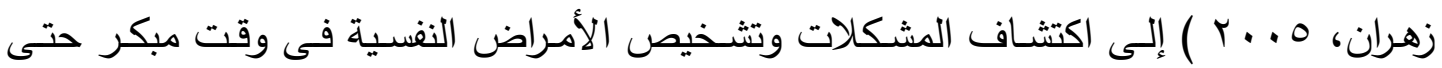
يتسنى اتخاذ التدابير الخاصة الفعالة تجاهها فى وقت مناسب ومن الأسباب التى دفعت الباحثة لهذه الاراسة: 1- تجنب بعض وسائل جمع المعلومات مثل التقارير الذاتية عن المفحوصين لتجنب الوقوع فى الملاحظة التى أشار لها عبد الرحمن العيسوى (1997 ) من قد يكون التشخيص خاص بالوالدين وليس الطفل 
r- الإستتاد إلى وسيلة تشخيص إسقاطية ( الرسوم ) حيث تسمح للطفل التعبير بحرية عن مكنوناتة الداخلية وتجنب الإندفاعات النفسية لديه

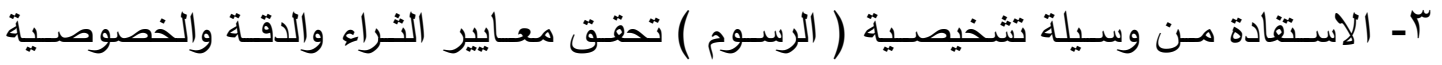
للمعلومات عن الحالة لزيادة فاعلية عملية التثخيص ع- توفير بيانات ومعلومات عن الحالة أكثر تعبيرا عن ذاته من الوسائل التشخيصية الأخرى 0- ونظرا لطبيعة عينة الدراسة "الصم ذوى صعوبات التعلم" والذين يفضلون المعومات البصرية عن غيرها (Edward\&Crocker (,2008 ؛ Moores,2001 (Vuuren 1995)

\section{أهســاف السدراسـة}

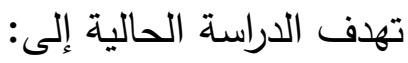

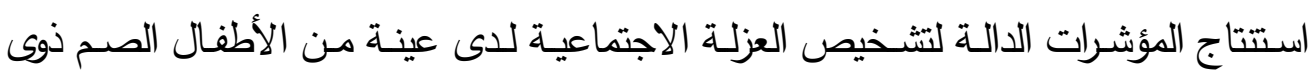
صعوبات التعلم عند استخدام اختبار رسم المنزل والثجرة والثخص واختبار رسم الأسرة فى التشخيص.

\section{أهميسة الدراسبسة}

تكمن أهميـة الدراسـة الحالية فى الجانب الذى تتصدى لدراستة حيث أنها تسعى لدراسـة

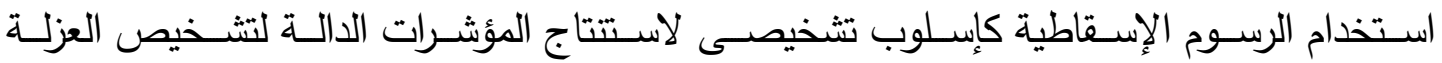

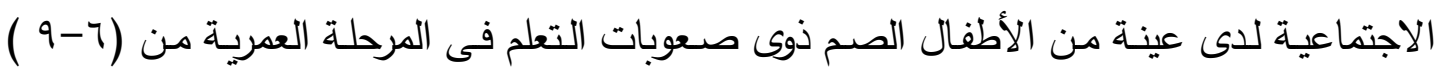
سنوات ولا شك أن هذا الجانب ينطوى على أهمية كبيرة من الناحيتين النظرية والتطبيقية كما يلى :

\section{أ) الأهمية النظرية}

1- لاحظت الباحثة من خلال مراجعة البحوث والدراسات فى مجال التربية الخاصـة ( فئة الصم

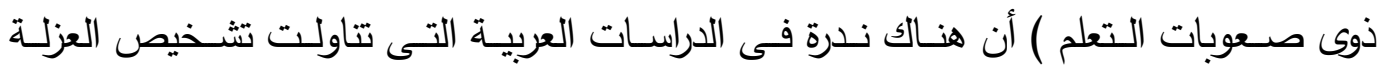

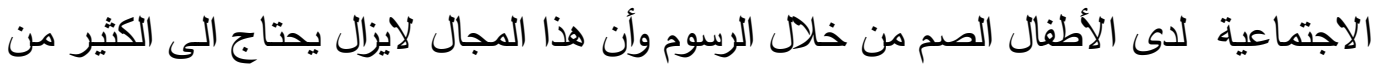
البحوث والدراسات التى تتناولة من زوايا وجوانب مختلفة ومتعددة وخاصـة بالنسبة لفئة الصم ذوى صعوبات التعلم ومن ثم تعبر هذة الدراسة عن حاجة البحث العلمى إلى القيام باستخدام

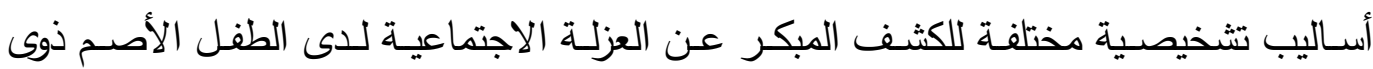
صعوبات التعلم فى المرحلة العمرية من (7-9 ) سنوات r- تحاول الدراسة الحالية تقديم المساعدة التى يمكن أن تؤدى لفهم أفضل لأطفالنا وإعادة البناء النفسى للأطفال الصم ذوى صعوبات التعلم 
r- تقديم إطار نظرى عن الطفل الأصم ذوى صعوبات التعلم يعرض خصائصة وكيفية التعرف علية نظرا لعدم وجود دراسات عربية تحدثت عنه من قبل

\section{ب) الأهمية التطبيقية}

1- تحديد المؤشـرات الدالـة لتشخيص العزلـة الاجتماعيـة لدى الأطفال الصـم ذوى صـوبات

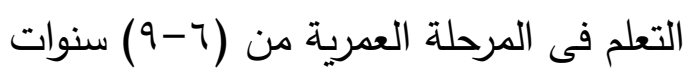

r- يمكن أن تسهم هذة الدراسة بشكل فعال من خلال تحليل رسوم الاطفال وتثخيصها فى فهم أهم الأسباب التى تؤدى إلى العزلة الاجتماعية والعمل على كثفها وتحسينها

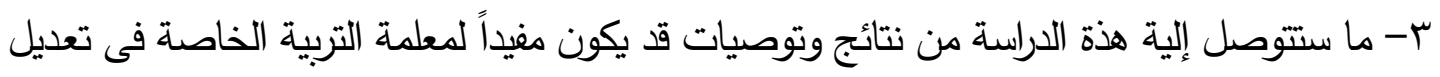

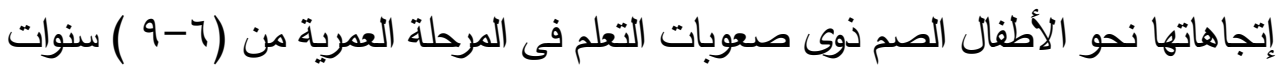

\section{مصطلد مـات الدراســـة}

\section{Indicators المؤشرات}

هى "علامات ودلالات تستخدم لمراقبة وقياس وتقييم مدى التقدم نحو تحقيق الهدف،

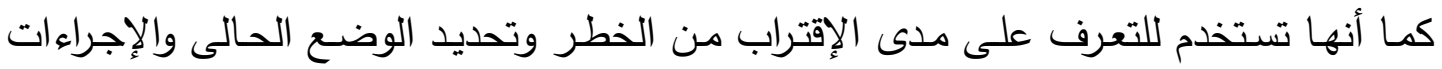

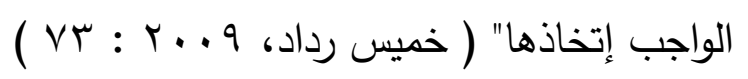

\section{riagnosis r التشخيص}

هو "الفن أو السبيل الذى يتسنى به التعرف على أصل وطبيعة ونوع المرض وعملية

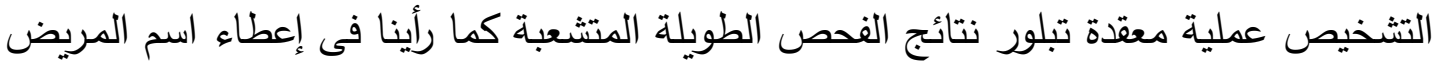

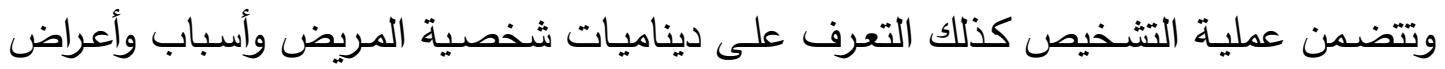

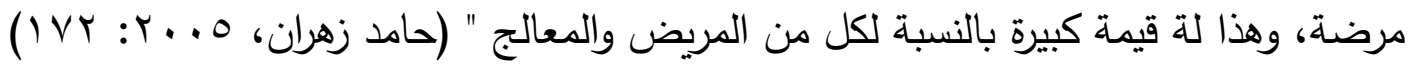

\section{Social Isolation ب- العزلة الاجتماعية}

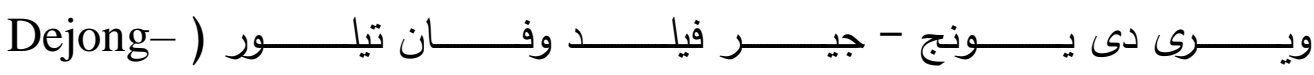

(Gierveld\&Vantilburg,1990 ) أن العزلة الاجتماعية هى مدى ما يشعر به الفرد من وحدة وانعزال عن الآخرين وابتعاده عنهم، وتجنبه لهم، وانخفاض معدل تواصله معهم واضطراب 
علاقاته بهج، وقلة عدد معارفه وعدم وجود أصدقاء حميمين لله، ومن ثم ضعف شبكة العلاقات

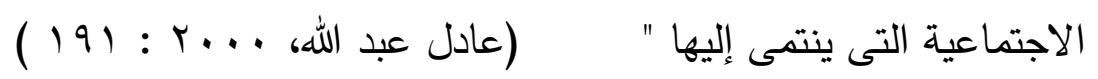

¿- الطفل الأصم ذوى صعوبات التعلم Deaf with learning disabilities

يعرف (Pallack, 1997) الطفل الأصم ذوى صعوبات التعلم بأنة "ذلك الطفل الذى يعسانى بالأضـافة إلى الصـمم مـن مشـكلات صـعوبات التعلم المتمثلـة فـى مشككلات الإدراك البصـرى، مشـكلات الأنتبـاة، مشـكلات الإدراك الحركىى، مشـكلات الأحتفـاظ بالمعلومـات،

مشكلات الذاكرة وعدم القدرة على تعلم المفردات وعدم الأنتباة أثناء المهام ( الشرود) ".

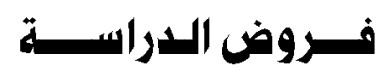

ا - يمكن تشخيص العزلة الاجتماعية للطفل الأصم ذوى صعوبات التعلم فى المرحلة العمريـة

$$
\text { من (7-9) سنوات من خلال الرسوم }
$$

ץ- لا تختلف مؤشرات تفاصيل رسوم الأطفال الصم ذوى صسوبات التعلم فى المرحلة العمريـة

من (7-9) سنوات لتشخيص العزلة الاجتماعية لديهم بتغير النوع مؤنث - مذكر)

"- تتطابق نتائج تشخيص العزلة الاجتماعية للطفل الأصم ذوى صسوبات التعلم فى المرحلة

العمرية من (7-9) سنوات من خلال رسومهم مع تشخيصها بأدوات قياس سيكومترية

\section{منهـسج الدراسية}

اعتمدت الدراسة على المنهج الإكلينيكى

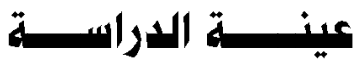

تضمنت الدراسة الحالية عينة استطلاعية، وأخرى أساسية وفيما يلى توضيح لذلك :

\section{أ) العينة الاستطلاعية}

تكونت عينـة الدراسـة الاستطلاعية مـن (Y) طفل وطفلـة مـن الأطفال الصـم وذلك بمدرسـة الأمل للصم وضعاف السمع ببنها، وتراوحت أعمارهم الزمنية ما بين (7 -9) سنوات ممن تتراوح درجة الفقد السمعى لديهم من ( • - • (q) ديسييل. 


\section{ب) العينة الأساسية}

تكونت عينة الدراسة الأساسية من (آ) من الأطفال الصم ذوى صعوبات التعلم وهم

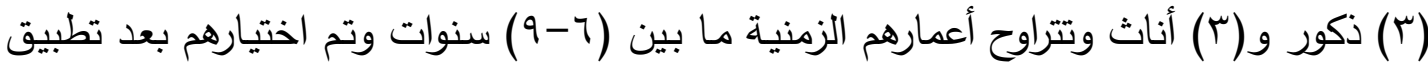

مقياس صعوبات التعلم عليهم

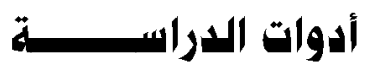

1- استمارة جمع البيانات للتلاميذ الصم ( وهذه الاستمارة تم أخذها من خلال بيان الحاله

$$
\text { فى المدرسة ) }
$$

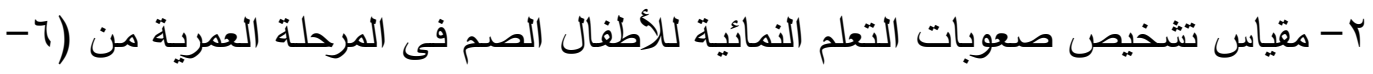

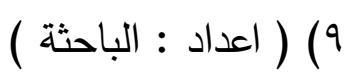

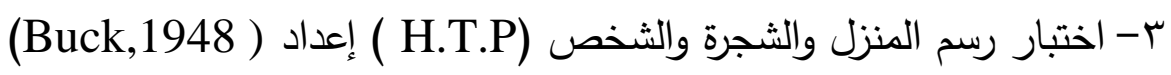
ع - اختبار رسم الأسرة إعداد بيرنس وكوفمان (Burns\&Kaufman 1970)

$$
\begin{aligned}
& \text { 0- الرسوم الحرة ( رسم خطر على بالك الأن - رسم حدث هام ) } \\
& \text { צ- أسلوب تحليل الاستجابات على الرسم }
\end{aligned}
$$

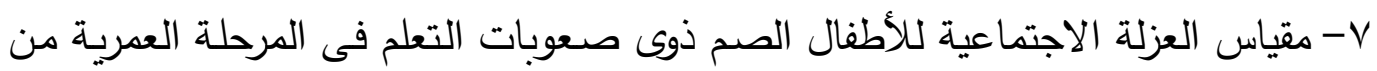

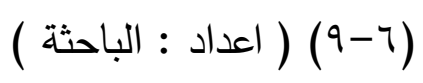

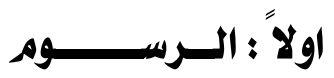

\section{تعريف رسوم لاطفال}

ورد الرسم في ذخيرة علم النفس على أنه " إحدى صور قوة التعبير والوسيلة التى بها

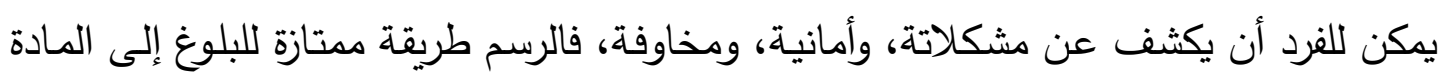

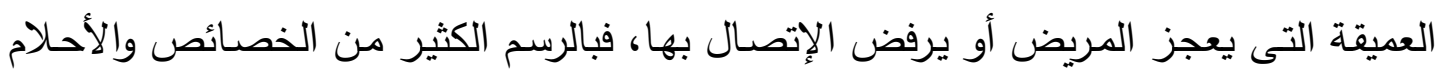

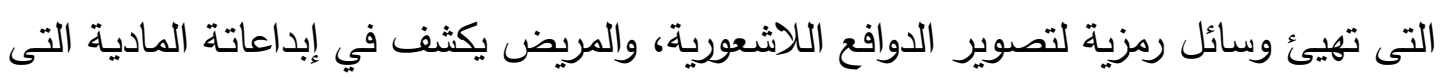

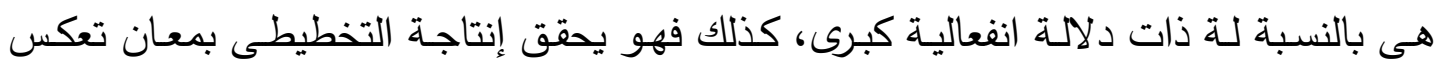

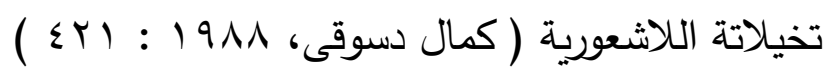

هذا المعنى وهذا الاتصـال يصل عالم النفس إلى فهم حالة الطفل النفسية والجسمية

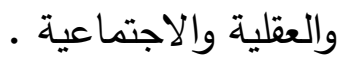


أما رسوم الاطفال فعرفها محمود البسيونى (190V، 19V ) بأنها "تلك التخطيطات الحرة

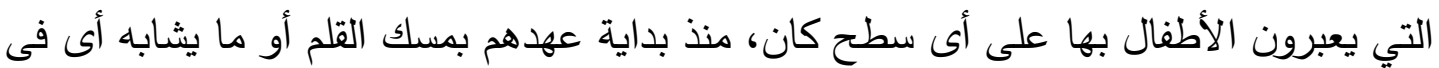

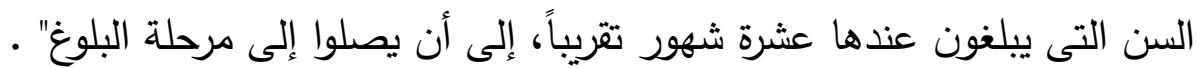

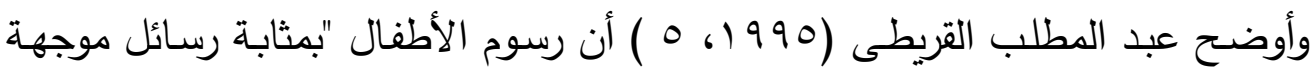

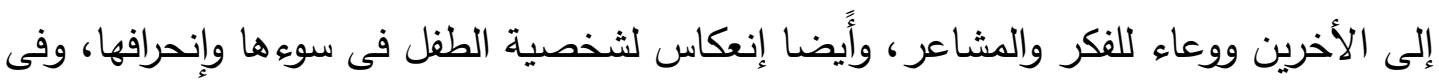

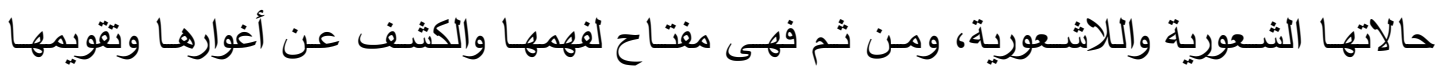

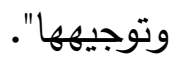

ويعرف عادل خضر ( 1991، (1) ) رسوم الاطفال على أنها "وسيلة الطفل الأكثر تعبيراً عن ذاتة، وهى أداة للتنفيس عن مكبوتاتة، ومن ثم فإن هذا الرسم الذى يقوم بة الطفل

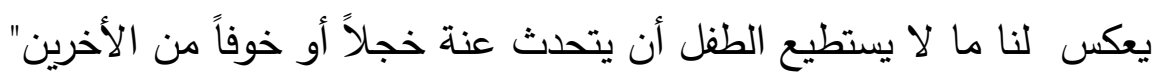

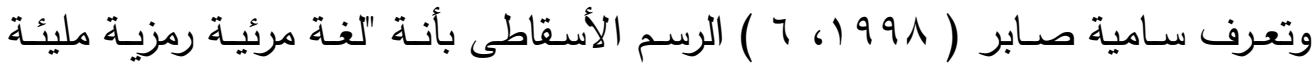

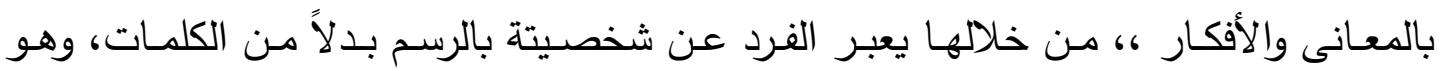

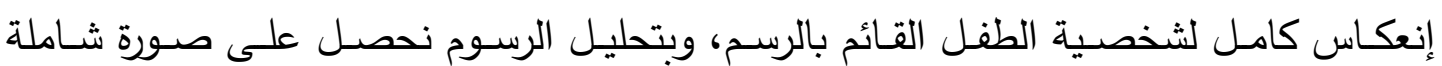
تفصيلية عن العالم الداخلى لهذا الفرد". وتوصلت أميمة جبر ( . . . ، ، ، ) إلى أن رسوم الأطفال "لغة رمزية تظهر فى نتاج خطى أو موجة ومن تجميعة يتم تكوين شكل، ومن خلال تحليل الثكل نستدل على شخصية الطفل على المستويين الثعورى واللاشعورى فى الجوانب الانفعالية والفكرية والاجتماعية"

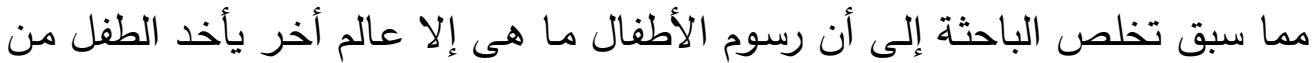
واقعة المليئ بالصراعات إلى عالم أخر مليئ بالأطئنان والراحة النفسية فيندمج فى هذا العالم التهال

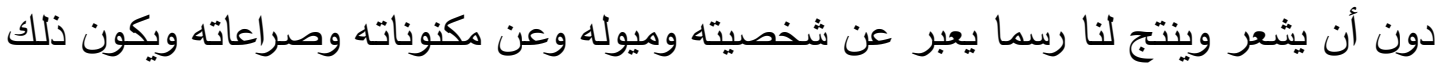

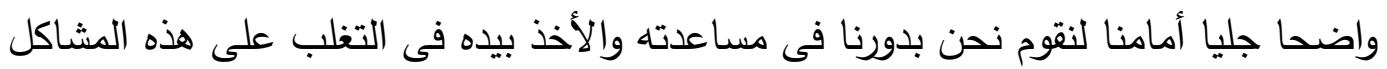

\section{الر سوم نـافذة على الشفصية}

كثيراً مـا نرى صغار الأطفال يعبرون بتلقائيتهم، المعروفة على جدران المنازل وفى لتى

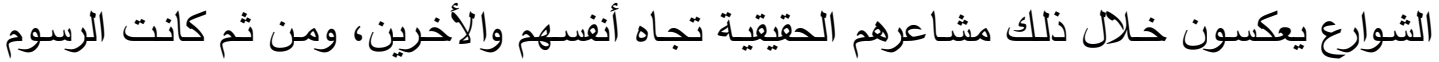
وسيلة ممتازة لارتياد عالم الطفل، في الوقت تاذى تكون فية اللغة المنطوقة عائق للأطفال فى

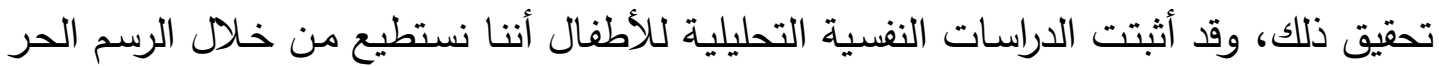


الذى يقوم بة الطفل أن نصل إلى المحتوى اللأشعورى عندة، والتعرف على مشكلاتة وما يعانية وكذلك التعرف على ميولة واتجاهاتة ومدى اهتمامة بموضوعات معينة فى البيئة التي يعيش البش فيها وعلاقاتة بالأخرين سواء فى الأسرة أو الرفاق أو الكبار . ومن ثم يعتبر الرسم أداة جيدة لفهم نفسية الطفل ومشاعره واتجاهاته ودوافعها وتصوره

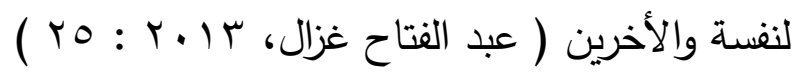

فالأنشطة الفنية التى يقوم بها الأطفال تعتبر إحدى الوسائل التى يجدون ذواتهم داخلها،

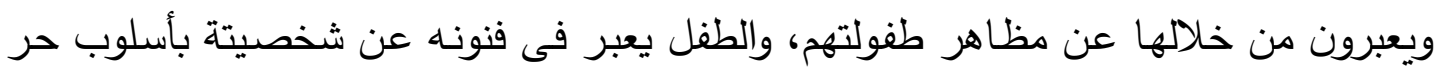

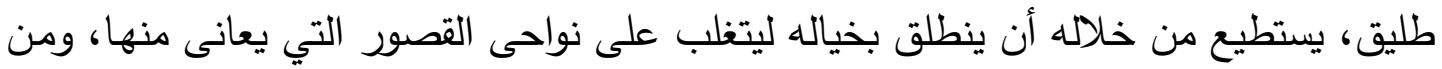
القيود التى تفرضها عليه حدود الزمان والمكان ـ فيقوم ببناء افكاره والتعبير عنها كما لو كانت

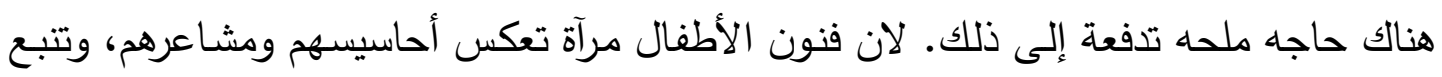

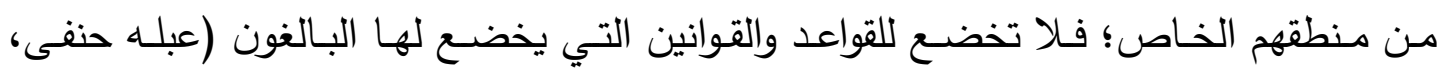
.(Ar:) $19 \wedge 9$

كما يؤكد محمود البسيونى (1974) (197) على أن معرفه شخصيه الطفل من خلال التعبير

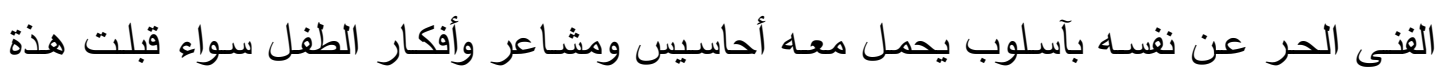

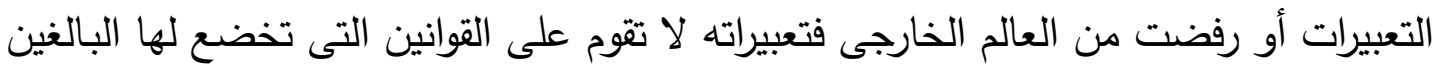

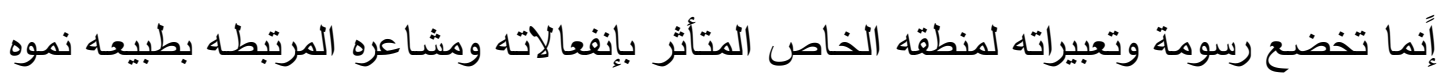
وبيئته التى يعيش فيها لذا يشير بياجيه إلى أن الطفل يرسم ما يعرفه لا لا ما يراه.

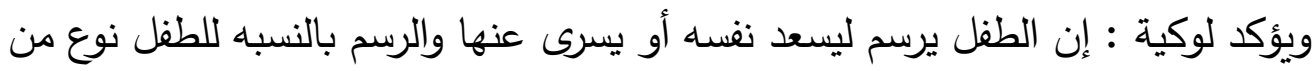
اللعب، شأنه شأن الألعاب الأخرى التى تستحوذ على أهتمامه (محمود البسيونى، ؛ ـ (199 (1) )

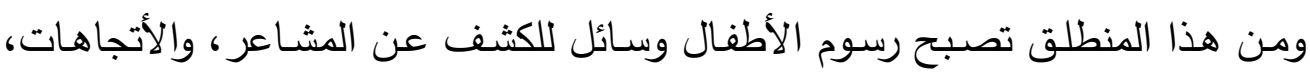

$$
\text { والدوافع، ومفهوم الذات، وصورة الجسم (عادل خضر ، } 991 \text { (1) ) }
$$

وبذلك تعتبر رسوم الأطفال أداة جيدة لفهم نفسية الطفل ومشاعرة وأتجاهاته وتصوره

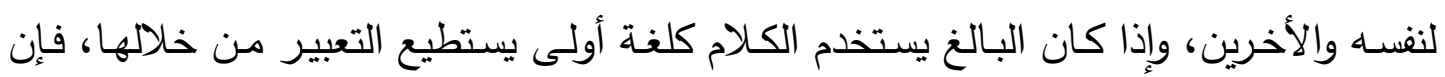

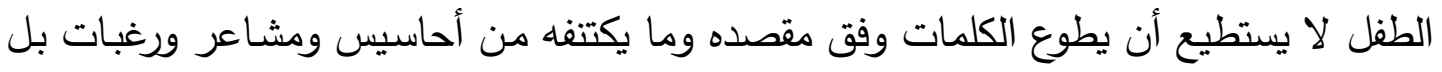

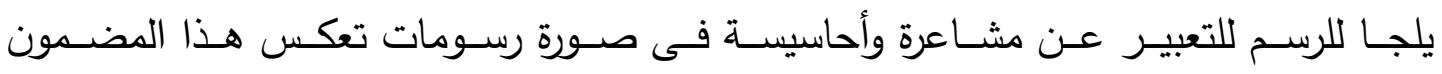
( kalberman paula \& may ,1988 ) 


\section{القيمة التشفيصية والتنبؤية الرسوم الإسقاطية}

للصله الواضحه بين شخصية الطفل ورسومه بدأ أهتمام بعض العلماء في العشرين

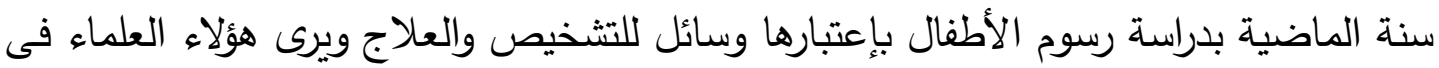

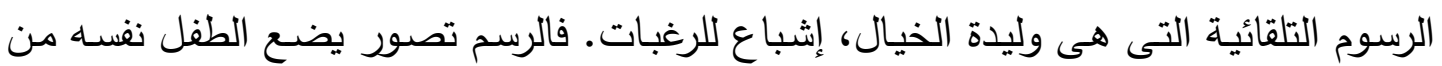

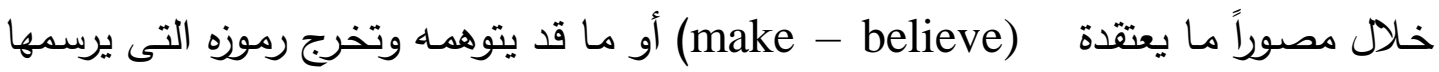

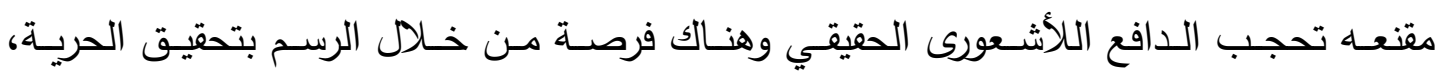

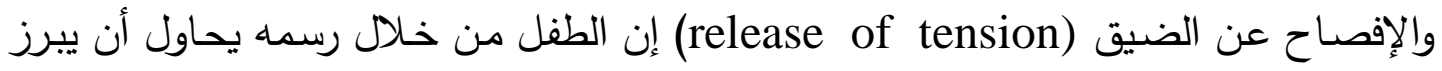
مشاعره التي لا تجد فهما من البيئة المحيطة وذلك فى محاولة لإيضـاح تلك المشاعر ،فمن

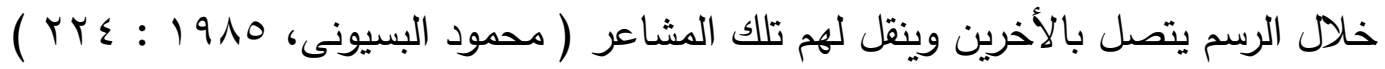
وبذلك تعتبر رسوم الأطفال، بصفة خاصـة، أيسر المداخل التعبيريـه للطفل لسـهولة

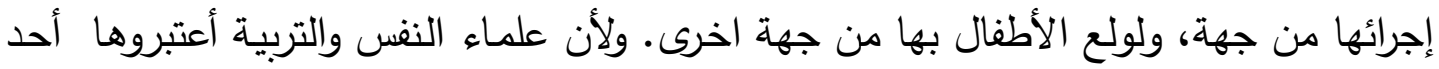
الدداخل المهمة التى تساعد على تحديد شخصية الطفل، وقد كانت الرسوم حتى وقت قريب من الأمور الغامضة المشكوك فى صحتها وجدواها فى حالات تحليل شخصية الأطفال ودراستها،

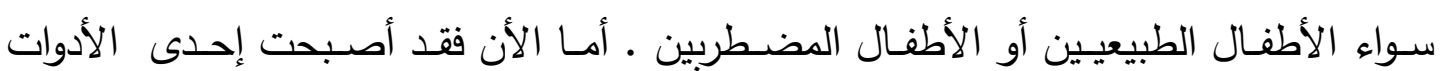

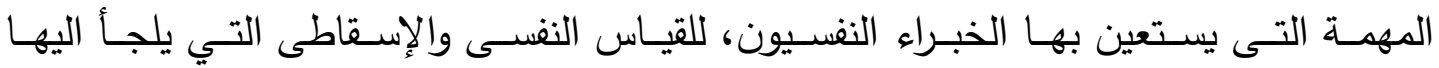
الأختصاصى النفسى فى عمله وقد كان أختبار رسم الثخص لكارين ماكوفر عام (9 19 (19 )

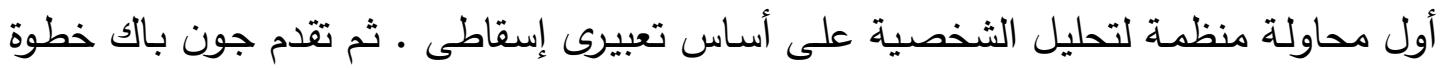

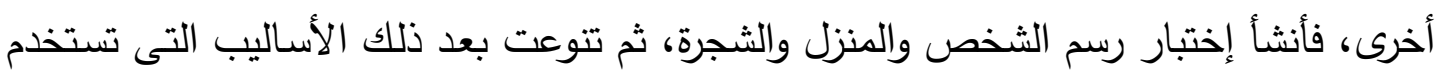

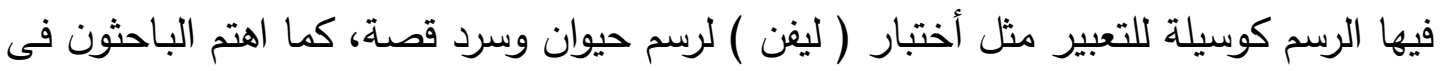
دراستهم برسوم الأطفال مثل ( لورين ) لقياس شخصيتهم والتعرف عليها ـ وقد توصل الثولر

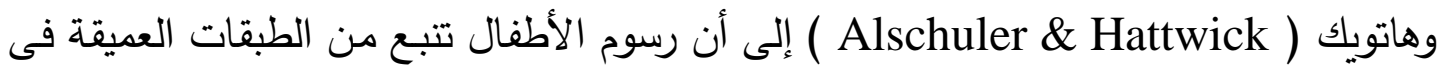
نفوسهم، وتستمد من البواعث والمشاعر الداخلية الكامنة داخلهم، والتى تشكل ديناميات السلوك الأنسانى ؛ فالرسوم هى تعبير مباشر عما بداخل الطفل، ولكل طفل أسلوبة المميز الغريزى فى

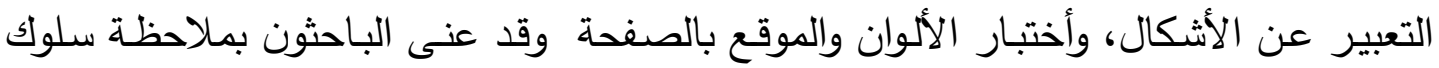

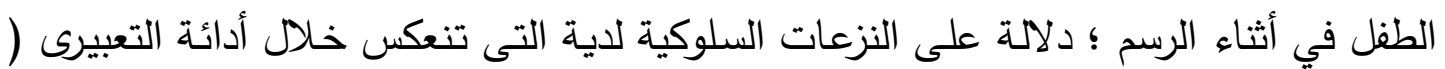

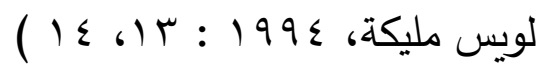


وتعد الرسوم الحرة للأطفال أكثر المجالات إتاحه للتعبير عن الكثير من خصائصهم

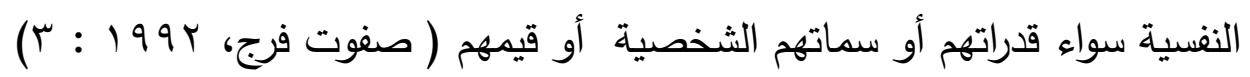

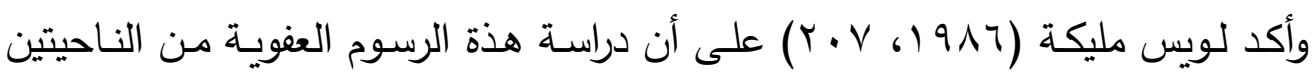
التشخيصية والعلاجية فهى تكثف عن الحاجات العميقة والصراعات الانفعالية والحياة التخيلية كما تسمح فى الوقت ذاتة للطفل في التنفيس أحيانا عن نوازعة العدوانية التي يصعب التعبي التعبير

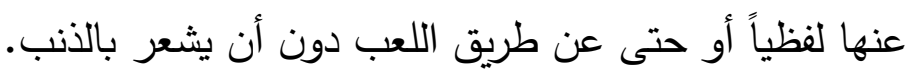

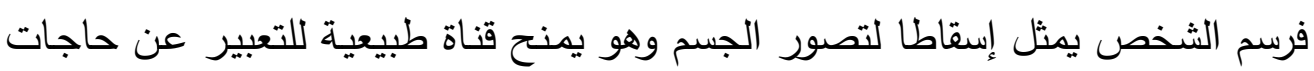

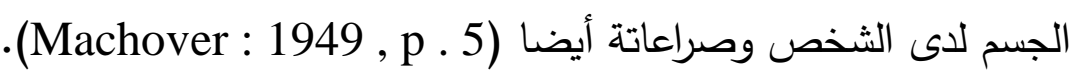
وإذا كانت Machover تفترض أن تصور الذات يسقط فى رسم الثكل الإنسانى، فإن Harris : يسلم بأن رسم الثكل الأنسانى هو عبارة عن إسقاط لتصور الذات (, 1963 Buck (pp . 433, 44 وقد أكد Bennett على أن بعض الخصائص المرسومة فى رسم الثكل، تعطى بعض

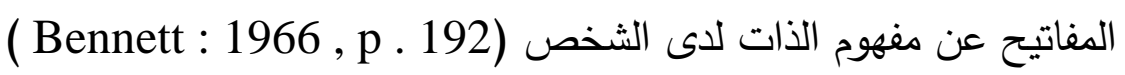

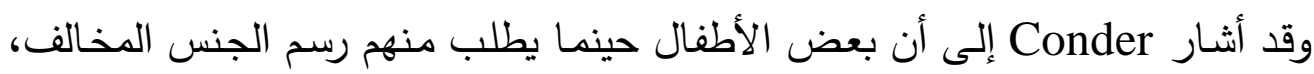

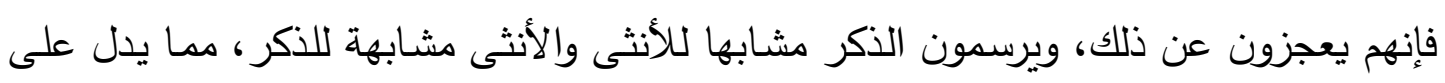

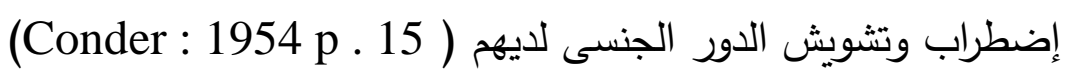

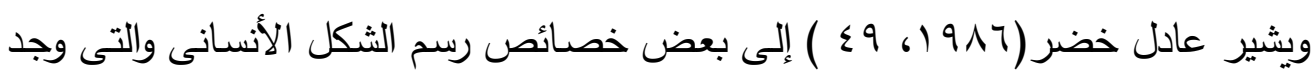

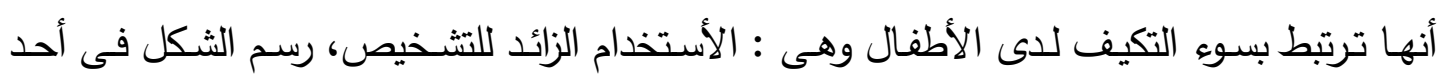

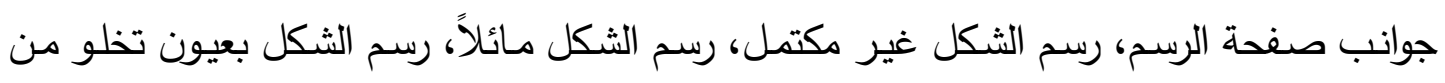
إنسان العين، أو رسمة بدون عيون، رسم الثكل بدون فم، أو بدون أذرع، رسم الثكل مشوهاً

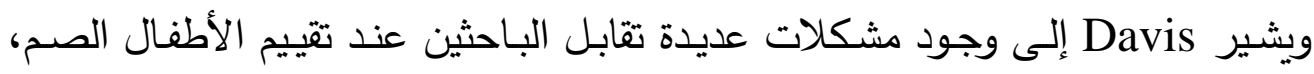
بسبب إعاقة اللغة لديهم، قبل أن يتعلموها، ومن هنا فإن استخدام الرسوم مع الصم يكون مفيداً

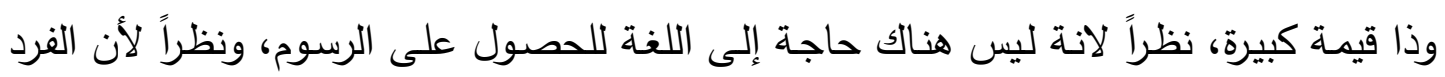

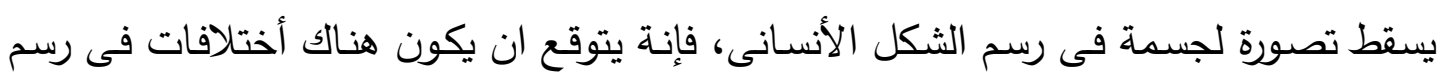

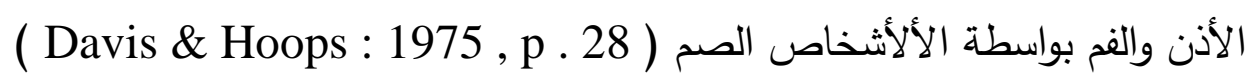


وقد لاحظت Machover خلال خبراتها الاكلينيكية، أن فاقدى السمع أو من لديهم

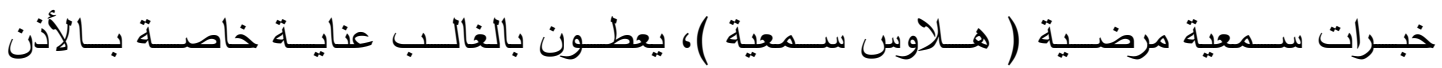

( Machover : 1987, p . 45)

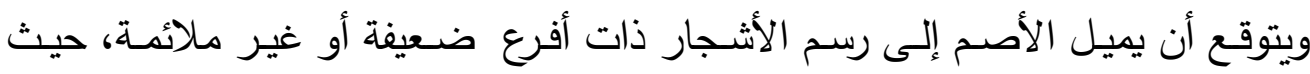

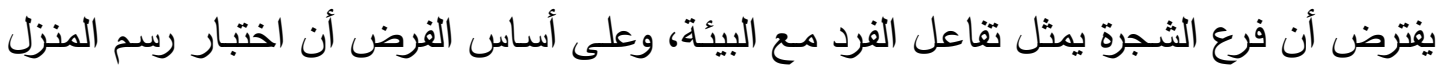
والثجرة والثخص يمكن من خلالة التمييز بين المضطربين والعاديين فإنة يعتقد أن الرسوم يمكن

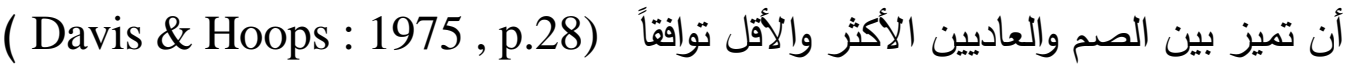
وأكثر الرسوم استخداماً فى دراسة الثخصية تأخذ أحد الأثكال الأربعة التالية :

$$
\text { رسم شخص ( Draw - a - person ) }
$$

ولا يطلب فيـة ابراز أية خصائص محددة ـ وتتضمن التعليمات أن يقوم الطفل برسم شخص كامل بما فى ذلك الجسم والأطراف لا الوجة فقط، وذلك فى صحيفة بيضاء فى حجم

$$
\text { الفولسكاب تقريباً ( 5, } 8 \text { × } 11 \text { بوصة في دئ }
$$

\section{(Draw - a - family ) رسم شخصين ( ذكر، أنثي )}

وهـو مطـابق لرسـم الثـــص، وحيـث تتـرك الحريـة للطفـل ليرسـم الجـس الــى لـى

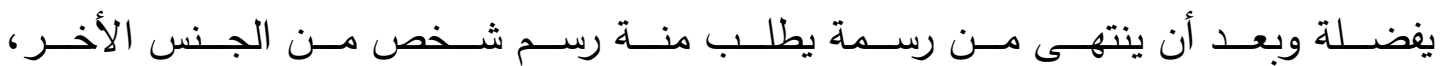
ويسـتخلص بعض البـاحثين دلالات مـن ترتيـب رسـم الجنسـين تتعلـق بـالميول الجنسـية

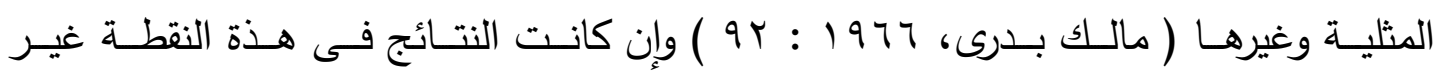
حاسـة وغير مقنعـة إلى حد كبير ، وهـى كغيرهـا مـن النتائج التى تعتهـ على أنطباعـات حسية لا يمكن التعويل عليها كثيرا ما لم تختبر بمنهجية مقبولة

\section{رسم العائلتة ( Kinetic Family )}

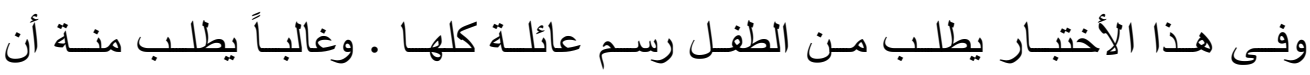

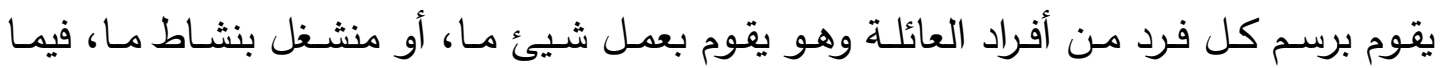

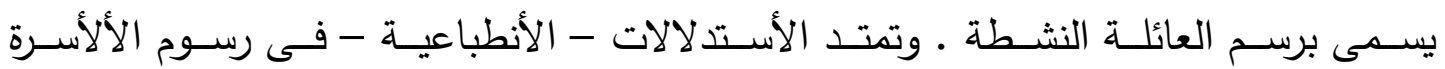

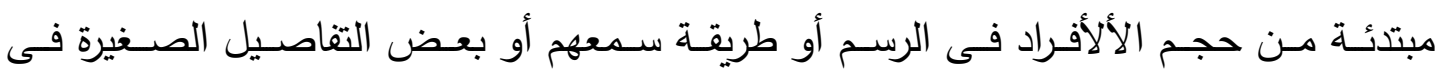

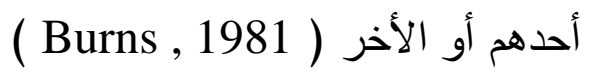




\section{رسم البيت والشجرة والشخص ( House - Tree - Person)}

وهو أختبار وضعة ( Buck , 1948 ) ويطلب فيـة من الطفل رسم بيت وشجرة

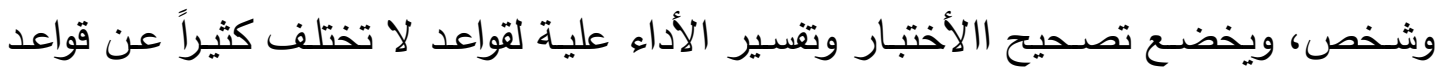

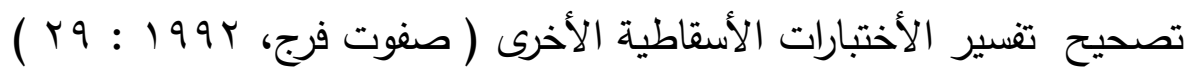

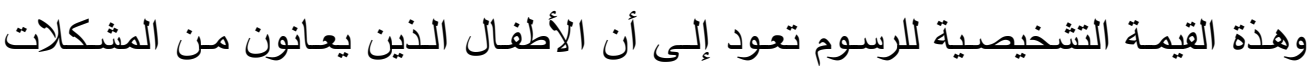
الانفعالية يمكن قيادتهم بسهولة عن طريق قيامهم بالرسم أكثر من تعبيراتهم اللفظية، فالطفل

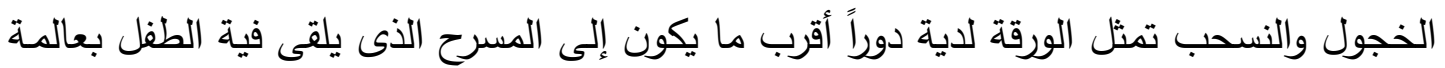

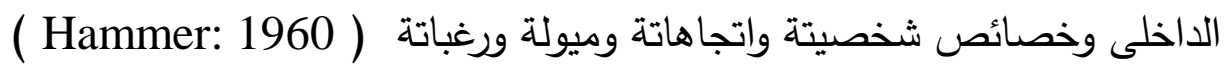
وبذلك تتضح القيمة التشخيصية والتتبؤية لرسوم الأطفال حيث تترك المجال خصئه وفياً أمام

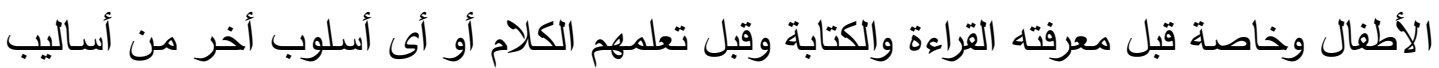

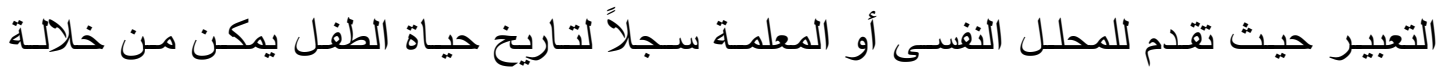
تثخيص المرض النفسى الذى ينتاب الطفل ومعرفة أسبابة فيقترح العلاج المناسب لة.

\section{ثانيا : الصم ذوى صعوبات التعله}

\section{تعريف الصم ذوى صعوبات التنعلم}

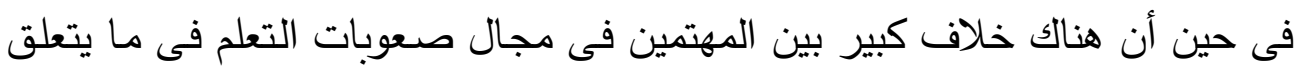
بتعريف صعوبات التعلم وينطبق الثيء نفسة على معلمى الصم، وهناك أدلة تدعم أن الأطفال

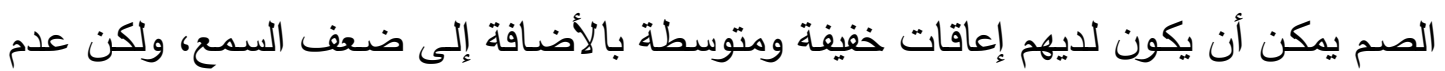

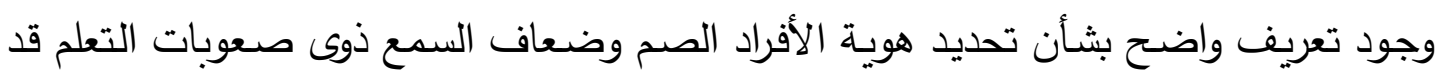

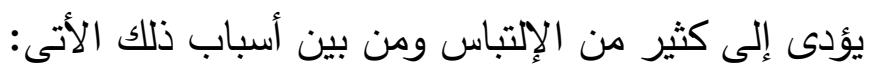

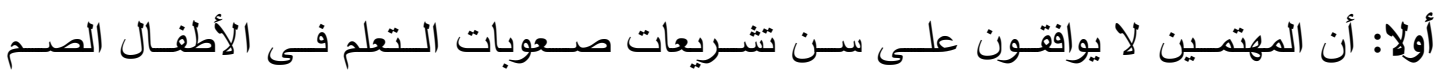

(Laughton, 1989; Bunch\& Melnyk, 1989; Powers et al .,1987) ثانيا: التركيز على المعالجة اللغوية للتعرف على التلاميذ العاديون ذوى صعوبات التعلم فى

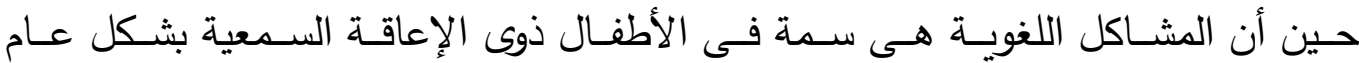
(Kretschmer\& Kretschmer, 1978; Plapinger\& Sikora, 1990; ومن الصعب تحديد ما إذا كانت مشاكل المعالجة 


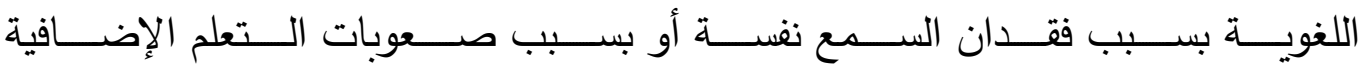

( Plapinger et al .,1990)

ثالثا: بسبب عدم وجود معايير محددة ولقد تم وضع الأفراد الصم وضعاف السمع تقديرات

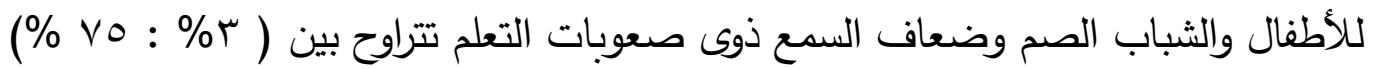
a ذذة الفئ

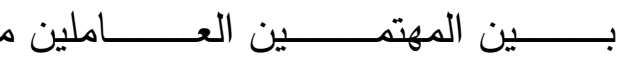
فيم-

(Morgan\&Vernon,1994;Plapinger et al.,1990 (السكان) ومن ثم فمن المهم وضع معايير خاصة للأفراد الصم من أجل تحقيق التوافق بين هذا التـاقض • وقد أقترح ( Laughton, 1989, p.74) تعريفا للأفراد المعاقين سمعيا ذوى صعوبات التعلم على النحو التالى: الى " أن الأفراد الصم وضعاف السمع ذوى صعوبات التعلم هم الذين يجدون صعوبة كبيرة

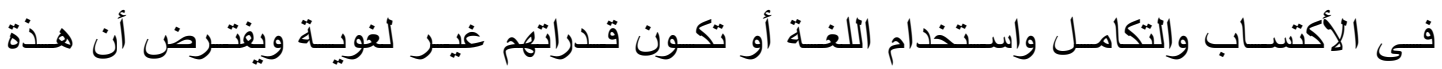
الإضطرابات تكون ناجمة عن وجود خلل فى الجهاز العصبى المركزى، وضعف السمع الحس عصبى للأجهز الطرفية وليس ذلك من قبل أى حالة حصرا ـ فظروف الحالة يمكن أن تختلف فى مظاهرها ودرجة الخطورة ويمكن أن تئثر على التعليم والأتصالات والثقة بالنفس والتتشئة الإجتماعية أو أنشطة الحياة اليومية فى جميع مراحل الحياة ".

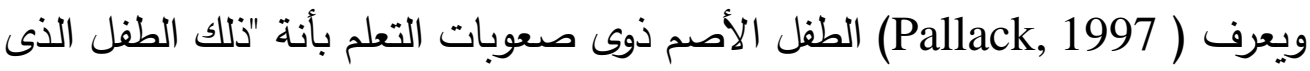

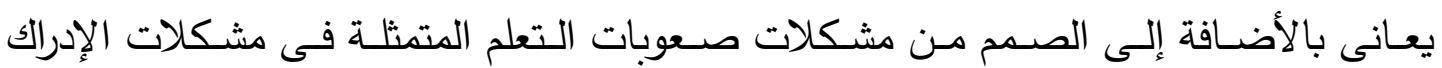

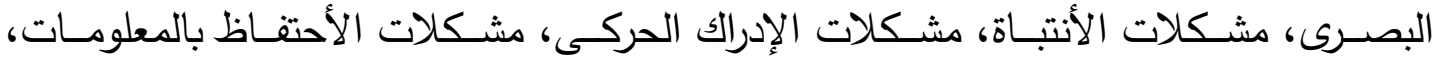
مشكلات الذاكرة وعدم القدرة على تعلم الدفردات وعدم الأنتباة أثناء المهام ( الشرود ) "

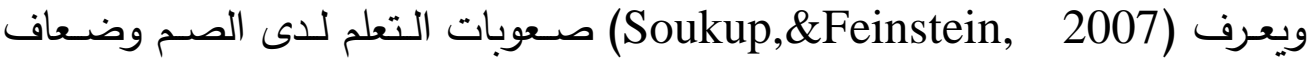

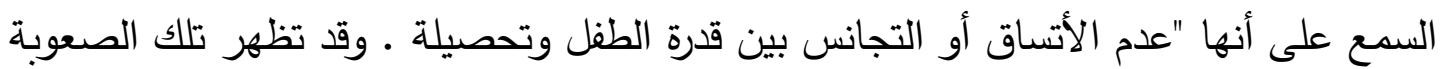
فى الضبط الدرسى وقد ترتبط بمشكلة فى مادة دراسية أو أكثر"

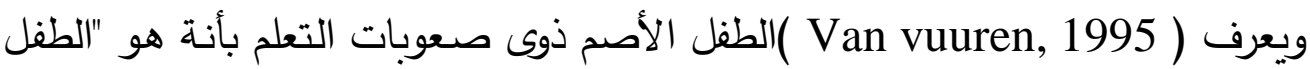
الذى يكون لديـة تماثل فى الإدراك الحس حركى مـ حيث المدخلات البصرية والمخرجات الحركية والتى تكون بسبب إعاقتة والقصور فى واحدة من الحواس السمعية أو البصرية يؤدى الدي

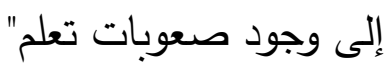




\section{تشفيص الأطفال الصم ذوى صعوبات التعلم}

يذكر ( Krywko,2014 ) أن تشخيص صعوبات التعلم فى الأطفال الصم وضعاف

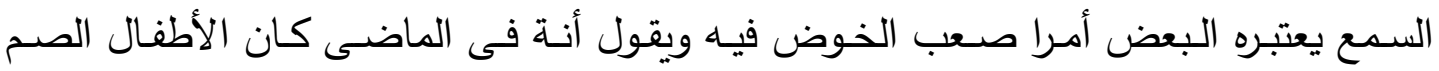
وضعاف السمع يفترض تلقائيا أنهم يمتلكون صعوبات تعلم بسبب فقدان السمع الموجود لديهم وضعف اللغة والكلام ونتيجة لذلك ظهر قانون IDEA ( . . r ) الذى ينص على تصنيف صعوبات التعلم والمعروف بأسم قانون التعليم للأفراد ذوى الإعاقات. ويذكر كلا من (G.W.mauk\&P.P.mauk 1993;Morgan\&Vernon 1994) أن الطفل الأصم أو ضعيف السمع هو أكثر عرضة لصعوبات التعلم من الطفل العادى وذو

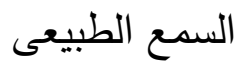

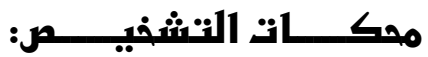

فى دراسة أجراها ( Van vuuren,1995) على مجموعة من الصم وضعاف السمع وتتراوح

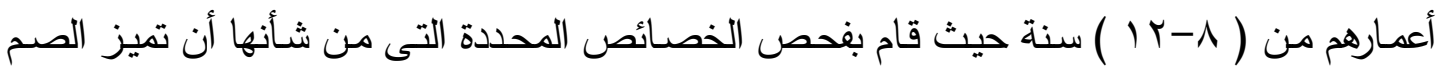
وضعاف السمع ذوى صعوبات التعلم عن الصم وضعاف السمع الذين لا يمتلكون صعوبات تعلم وتم العثور على (• () خصائص للصم وضعاف السمع ذوى صعوبات التعلم وهى: إنها توجد في البنين أكثر من البنات وذكر الباحث هنـا أنـة لا بـ من عقد دورات تدريبية داخل الددرسة ومراكز التدريب التبن

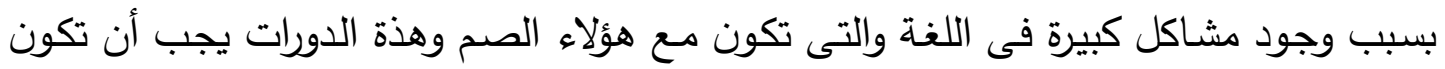
موجهة ومشدد عليها ويجب أن يكون عمل المسئولين والأجهزة جيد وبشكل فعال وذلك للكئ للوصول

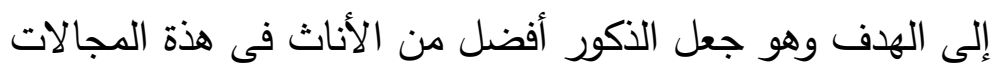
كانت تظهر فى الأطفال الأكبر سننا من أقرانهم ويذكر الباحث فى هذة النقطة أن أرتفاع العمر الزمنى لصعوبات الهربات التعلم عند الأطفال يكون

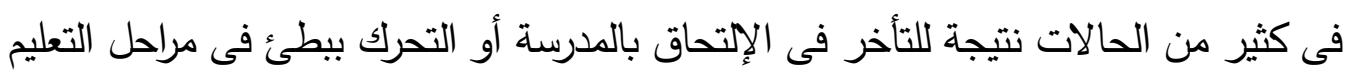
المشاكل الطبية ليهم تكون أكثر بروزا مع وجود أثار سلبية على الجهاز العصبى المركزى

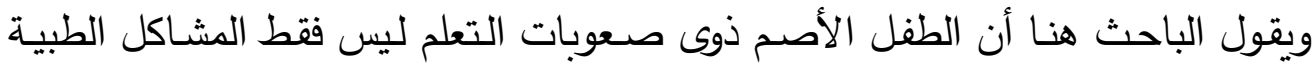
وخاصـة عند الولادة هى المتحكمة فية ولكن معظم هذه المشاكل قد تئدى إلى وجود خلل فى لإلى الجهاز العصبى المركزى والذى بدورة يؤدى وجود إختلالات فى الأعصاب والتى بسبيها تتتج 
عنهـا صـعوبات التعلم لـذا تعتبـر التجـارب الفسيولوجية العصبية ذات أهميـة قصـوى لجميـع الأطفال الصم

\section{المناخ التعليمه السلبى هو الأكثر بروزا لديهم}

وهذا المناخ السلبى كان نتيجة ضعف العلاقة بين الأم والطفل فقد وجد أن كل الأطفال الصم يعتمدون على إيجابية المناخ التعليمى الذى يشعرهم بالأهتمام والأمان وهذا يعتبر حافزا رئيسيا لهم بالأضافة إلى أن تكون مهارات التعليم متطورة بشكل كامل وإرشادات خاصة للوالدين لكى يعلموا أن لهم دور مهم ورئيسى فى مواجهة مشاكل التعليم

ضعف الأنجازات المدربسة

كما هو متوقع يوجد ضعف فى الأنجازات المدرسية لدى الأطفال الصم ذوى صعوبات التعلم عن أقرانهم وهذة التجارب المتكررة بالفشـل يمكن أن تئٔثر على صسورتة لذاتـة بالسـلب وكذلك على عمليات النمو لدية ولذلك فإن صعوبات التعلم عند هؤلاء الأطفال الصم يجب أن يكون لها إسلوب تعليمى خاص وخاصة فى مجال الأتصال

\section{إنـفناض الدافهية وتوجة ضعبف نهو المخاطر}

يتضح لدى هؤلاء الأطفال إنخفاض الدافعية بكل مستوياتها وتوجة ضعيف نحو مواقف واتف الخطر وهذا بدورة لة تأثير سلبى على التقدم المدرسى بشكل عام

\section{ضعف الإدراكالبصرى ومهارات التكامل البصرى}

الأطفال الصـم وضـعاف السمع ذوى صـوبات التعلم يوجد لديهم ضـف في الإدراك البصرى وذلك يؤثر بشكل سلبى على عملية القراءة والكتابة فيجب إعطاء عناية خاصـة لهؤلاء الأطفال لكى يتم إستيعاب ضـفهم فى الفصول الدراسية فضلا عن العديد من الأخطاء التى

يمكن القيام بها

\section{الأطافال الصم ذوى صعوبات التعلم بففضلون المعلومات البصربة}

إن الطفل الأصم ذوى صعوبات التعلم لا يستطيع الحصول على المعلومات عن طريق إلقـاء سـعـه لكى يسـمع ولا سـرعة القراءة تمكنهم مـن التواصـل والتعلم بنجـاح فهم يفضـلون الإتصال المرئى مثل الأشارات أو الأملاء اليدوى وهذا ضرورى فى البيئة المدرسية عن طريق تأزر الفم والأذن معا. 


\section{صعوبات التعلم لدى الأطفال الصم تسبب لهم ضعف في استخدام مهارة لغة الأشارة}

على الرغم من أنهم يفضلون استخدام لغة الأشارة إلا أنهم لا يستخدمونها بمهارة كبقية المجموعة وبذلك لا يمكن استخدامها مع مجموعة واحدة لأنها سوف تكون قادرة على الفهم وهذا يعقد تقديم العون والمساعدة لهم وتؤكد على حقيقة أن ما يفهمونة يجب أن يرصد خطوة بخطوة. فالرسائل الخطية تشبه تصاعدية لغة الكلام والتى سوف تكون عظيمة فى مساعدتهم فضلا عن استخدام الكمبيوتر للأطفال الأكبر سننا . أسنال

\section{ضعف مستوى النشاط والتركيز}

هذان العاملان هما من أبرز العوامل التى يمكن من خلالها التعرف على الطفل الأصم ذوى صعوبات التعلم ـ فغالبية صعوبات التعلم عند الأطفال الصم كانت بسبب ضعف قدراتهر على التركيز مما أدى إلى عدم تتمية اللغة لديهم وضـاع منهم الكثير من الفرص وبذلك لا تتطور لديهم أى وسيلة من الوسائل التى يمكن أن يتعلموا بها لها لهايه

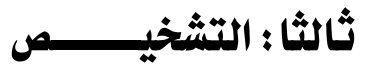

ويقصد بعملية التشخيص Diagnosis "تحديد طبيعة أو نوعية الأضطراب أو المرض ومقدار شدتة، وذلك بالنسبة للمرض أو للأعراض أو لأية عملية مرضية أو معتلة وبعبارة أخرى التشخيص يقصد بة عملية وصف وتصنيف للأضطرابات، كما يتضمن الخطوات والإجراءلت والوسـائل التى تتخذ من أجل تحديد الأضطراب الخـاص الذى يعانى منـة المريض" . (عبد

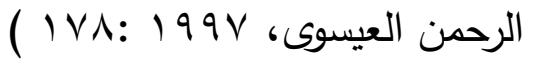

Ethical Guidelines of American وقد حدد الجمعية النفسية الأمريكية Association of Psychology

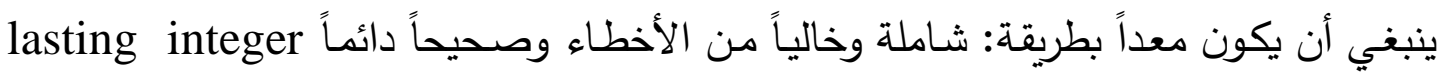
ومبني على أساس نظرية الاختبارات، ومرجع إلى معيار مناسب وملائم للتبليغ ومراع لصفات الأشخاص المعنيين وذلك فيما يتعلق بالجنس والسن والتوجه الجنسي والإعاقة واللغة والوضع التع الاقتصادي الاجتماعي ( - APA,1992, P..1603 ) (عن Röhrle,2008 .) 


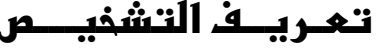

"هو تلك الإجراءات المستخدمة للحكم على طبيعة الإعاقة - إن وجدت - وعلى سبيها

$$
\text { المحتمل" ( هارجروف وبوتيت، هو الاجراءت } 911 \text { ) }
$$

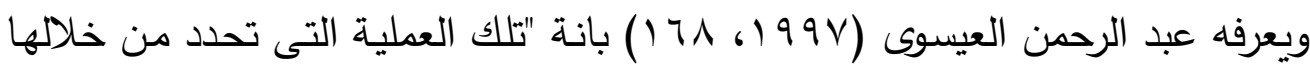

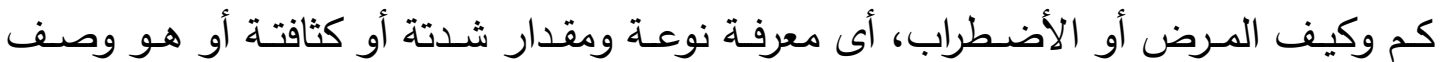

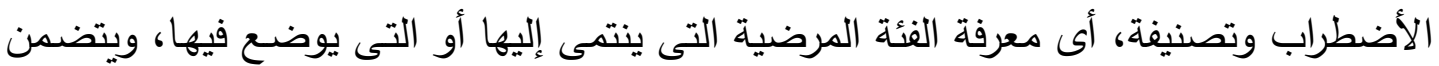

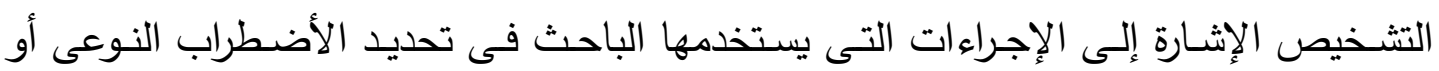

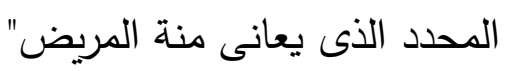

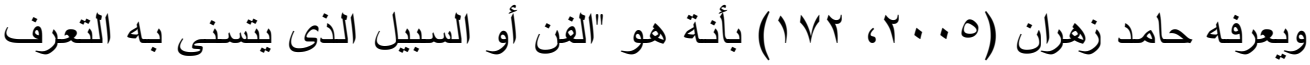

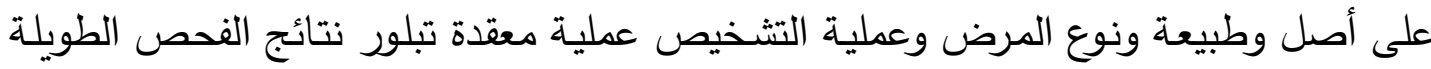

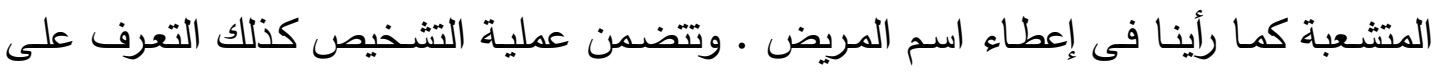

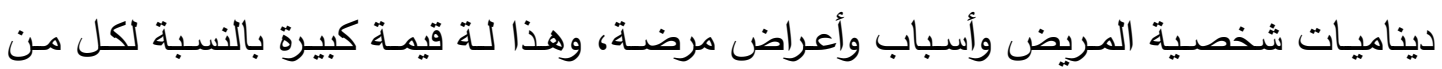

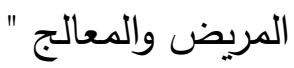

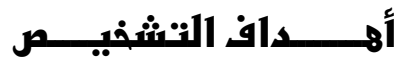

تذكر سامية القطان (9V9 (9V، 70) أن هدف التشخيص من الناحية العلمية معرفى ومن ثم عام فهو ليس بتكديس لتشخيصات جزئية بل فعل ختامى تتكامل فية التشخصيات الجزئية فى بناء هو الوحدة الكلية للعوامل الشارطة للسلوك، ومن الناحية العملية هدف التشخيص تقديم فرص للعمل وبكلمـات أخرى فإن هدف التشـخيص من الناحيـة العلميـة هو إمسـاك بالدلالـة الخاصـة لكائن فى موقف، والتثـخيص هو فعل ختامى وليس مجموعـة مـن التشخيصـات المتعاقبـة الجزئية ـ وعادة مـا تكون الملاحظة من الدقة والعمق بقدر مـا تكون عينة السلوك أعمق تمثيلا، فالمنهج الكلينيكى يقوم بتشخيص ما "يفلت" من الفرد لا كل ما يصدر عنة مثال ذلك أن يجيب المريض على تسعة وتسعين سؤلا بما يفيد توافقة بينما تنطوى إجابة فى السؤال

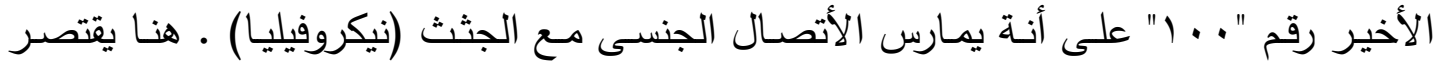

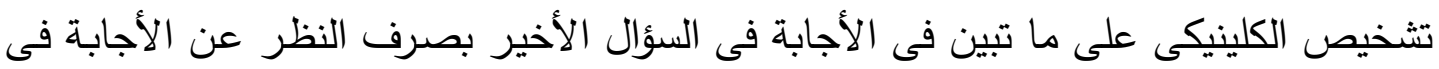

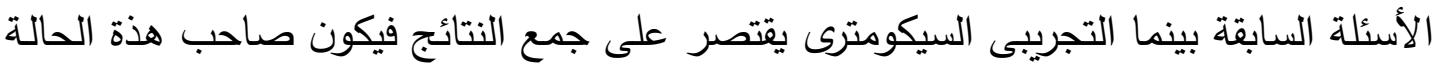

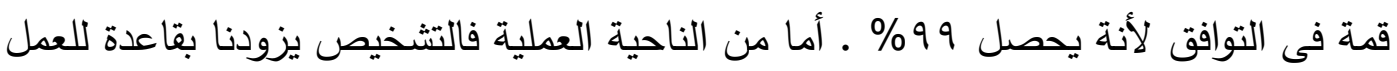




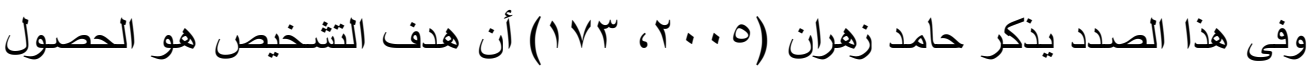

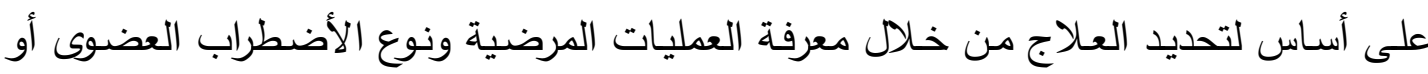
الوظيفى • وفى التثـخيص نلاحظ أن الأعراض تثـير دائهـا إلى خلل في التكوين النفسى التهى

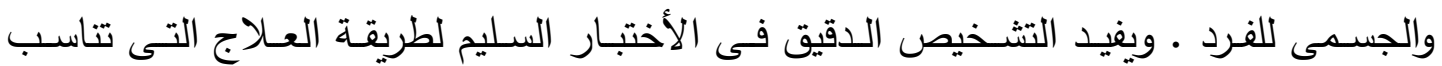

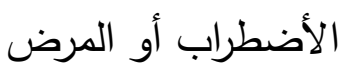

\section{Social Isolation : رابعا : العزلة الاجتماعية}

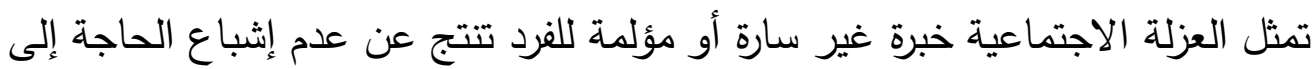

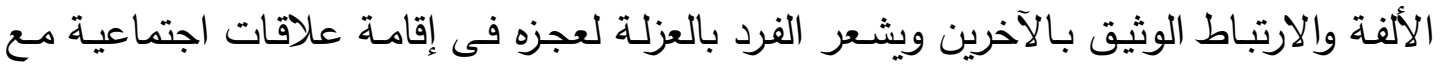
المحيطين ( عادل عبد الله، ... . : 19 1 ) . فهى خبرة وجدانية ضاغطة تؤثر على شخصية

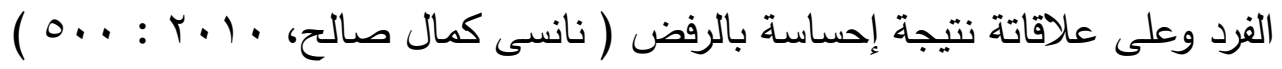

\section{تعريف العزلة الاجتماعيتة :}

إختلف الباحثين فى تعديدهم لمفهوم العزلة الاجتماعية الاجية : تصاعية

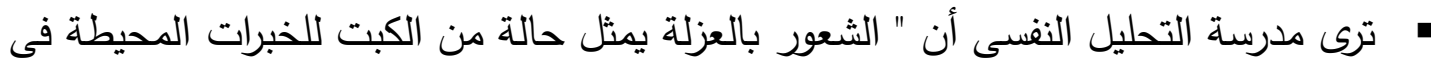

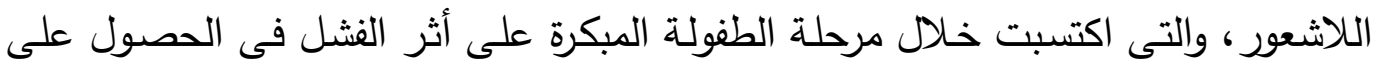

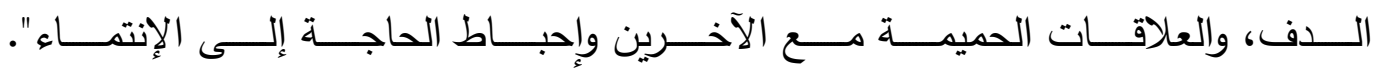
( ويرى دى يونج - جير فيلد وفان تيلور (Dejong - Gierveld\&Vantilburg,1990) " أن العزلة الاجتماعية هى مدى ما يشعر به الفرد من وحدة وانعزال عن الآخرين وابتعاده

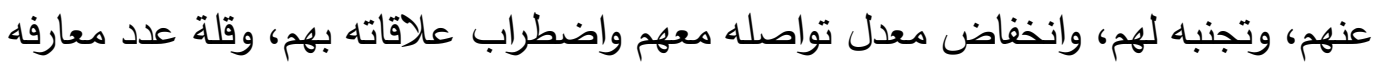

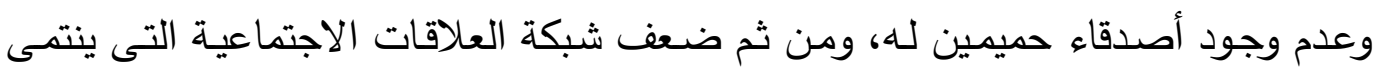

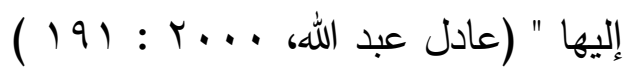

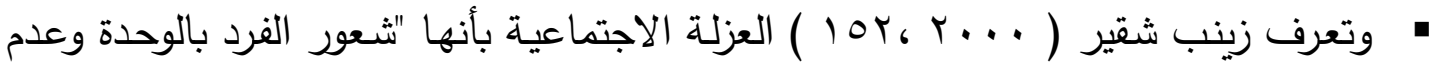

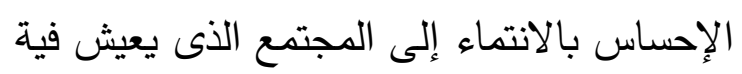

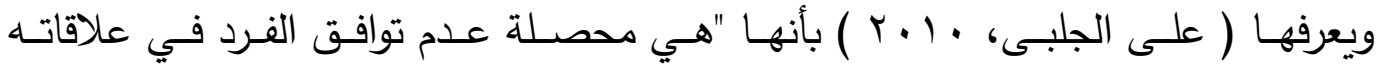

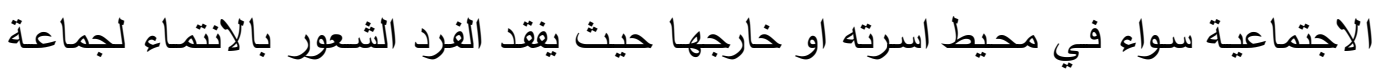

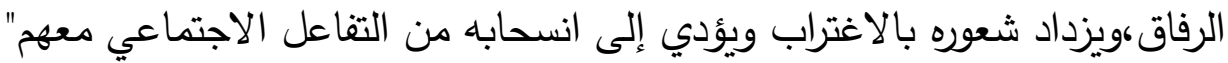


• وقد تبنت الباحثة تعريف ( الجلبي، 9 ( ) ) تعريفاً نظرياً لبحثها، ويعرف اجرائياً ( بأنها

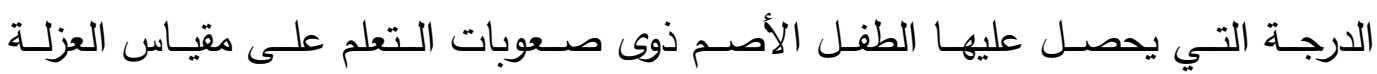

$$
\text { الاجتماعية ) }
$$

\section{العوامل التى تسبب العزلة الإتنماعية}

تتعدد العوامل التى تسبب العزلة الاجتماعية ـ فمنها عوامل ترتبط بالفرد، وأخرى ترتبط بالبيئة الخارجية ـ وهى كما يلى لئى

\section{العوامل المرتبطة بالفرد}

• الخجل : Shyness، ويشير الخجل إلى الثعور بعدم الإرتياح الشخصى وصعوبة التعبير عن الذات، والرغبة فى تجنب مواقف التفاعل الاجتماعى، والخجل قد يرجع إلى مشاعر

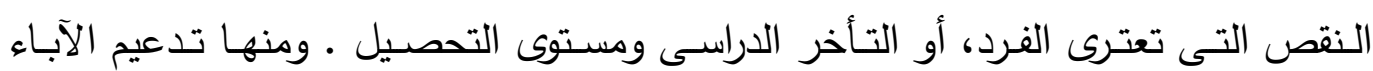

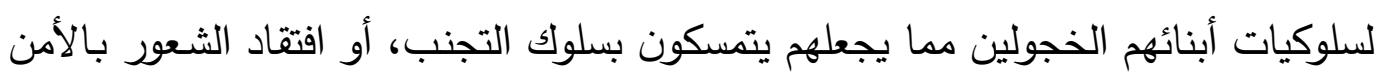

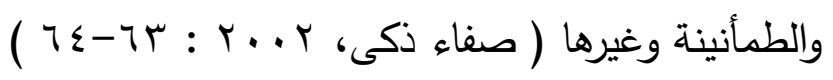

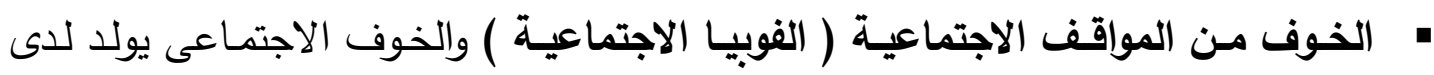
الأفراد نوعا من القلق قد يعقبة أو يلازمة اضطراب فى السلوك الاجتماعى .

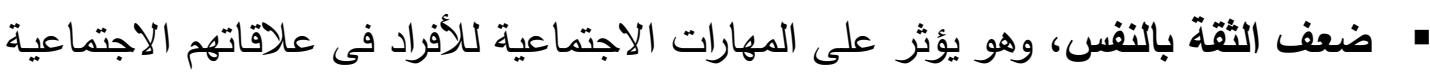
مما يساعد على انفصالهم وانعزالهم • وبالتالى احساسهم بالوحدة

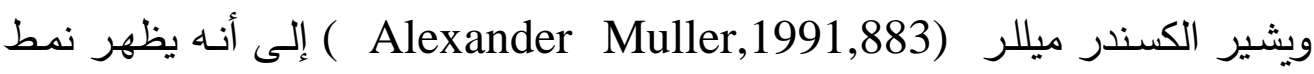
تسمية الذات كطفل منعزل عندما يتقبل الطفل المنعزل نفسه على هذا النمط، وذلك عندما يدرك المواقف من خلال شعورة بالخوف ونقده للذات • الحساسية الزائدة، وهى ترتبط بالخجل فالثخص الخجول شديد الحساسية للآخرين

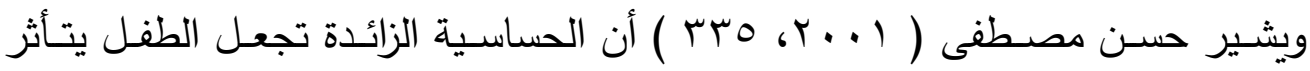
أكثرمن اللازم بالأحداث ويبالغ مبالغة لا معنى لها فى تلقى هذه الأحداث، ويعطى الهى الاشياء صدى لايستحقه، بالإضافة إلى ذلك فانه يتوقع ردود فعل غيرة من الناس قبل أن يعاملوه أو يتصل بهم فيخشى عن قرب أو عن بعد أن يؤذى الآخرين إحساسه 
• معانـاة الفـرد مـن بعض العيـوب الخلقيـة، أو امتلاكـة لبعض الصفات البدنيـة المتطرفـة كالقصر الثديد أو الطول الفائق أو النحافة أو السمنة

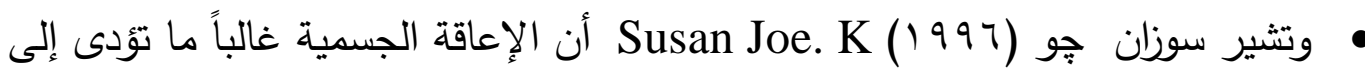
العزلة، فالإعاقة الظاهرة التى تجعل بعض الأطفال مختلفين عن غيرهم قد تؤدى بهم لأن يصبحوا حساسين جداً، فهم يتجنبون الآخرين حتى لايحدقوا بهم، أو يتحدثا عنهم

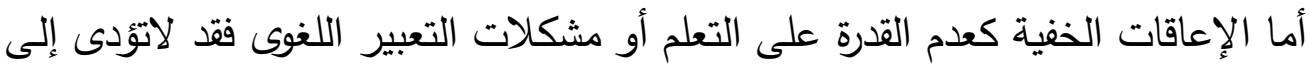

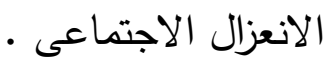

\section{العوامل التى ترتبطبالبيئة الفاريية :}

وهى عوامل اجتماعية ترتبط بالمجال البشرى الذى يحيا فيى الفرد وتتمثل فيما يلى :

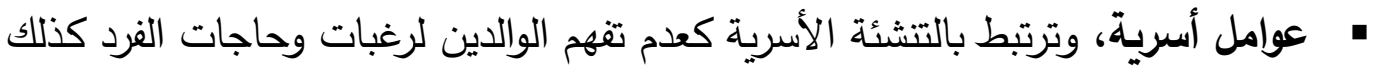

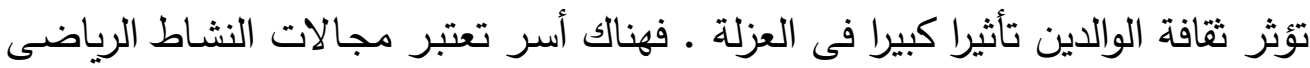

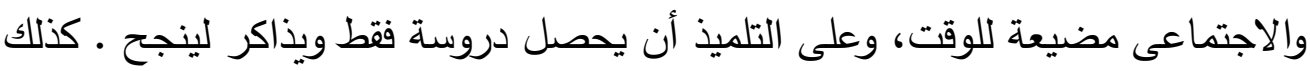

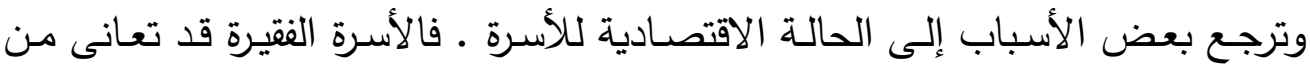

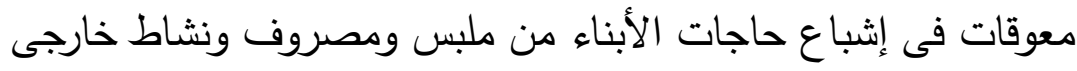
• جماعة الأقران، وعدم تقبل الأقران قد يخلق لدى الفرد إحساسا بالنبذ والرفض فتكون

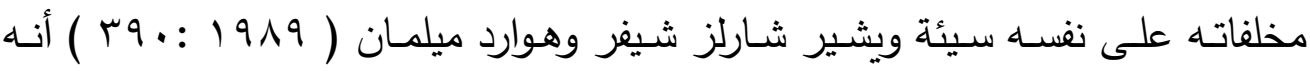
تحدث نواتج سلبية عندما تكون لدى الأبوين توقعات تتعلق بأصدقاء أطفالهما فهما

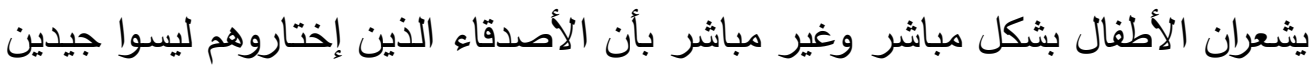

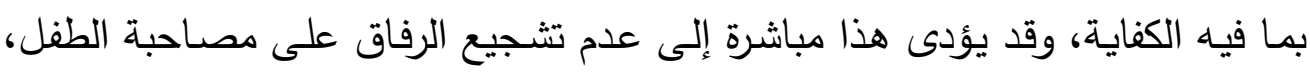
وأنهم يشعرون بأنهم غيرمرغوب فيهم من الوالدين

\section{نتسائســ الدراســة}

من تحليل رسوم عينـة الدراسة (ن =7 ) من الأطفال الصم ذوى صعوبات التعلم تم

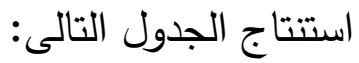


جلول( ) المعالجة الاحصائية للمؤشرات الدالة لتشخيص العزلة الاجتماعية (ن =7 ) للرسوم المقيلة

\begin{tabular}{|c|c|c|c|}
\hline النسبة المئوية & 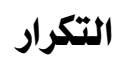 & 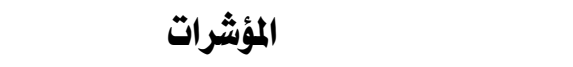 & 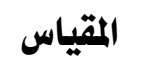 \\
\hline$\% 1$ & 7 & رسم الباب مغلق & 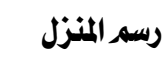 \\
\hline$\% 1 \cdots$ & 7 & رسم الباب علية قفل & \\
\hline$\% 77, \vee$ & $\xi$ & رسم النوافذ مغلقة & \\
\hline$\% ฯ 7, \vee$ & $\varepsilon$ & رسهم النوافذ عالية & \\
\hline$\%$. & $r$ & رسم النواقذ لها قضبان & \\
\hline$\% 17,4$ & 1 & حذف النوافذ & \\
\hline$\% 17,7$ & $\varepsilon$ & حجم المنزل صغير & \\
\hline$\%$ \%r, \& & r & رسم خط الأرض بعيدا عن الوحدة وانحدارة لأسفل & \\
\hline$\% \Delta r, 0$ & 0 & استخلاه اللون الأسود & \\
\hline$\% 17, \vee$ & 1 & رسم ثمرةواحدة فى الشجرة & رسه الشجرة \\
\hline$\% 17, \vee$ & 1 & رسمر طائر واحد يعيش فوق الشجرة & \\
\hline$\% r r, \xi$ & r & رسم خط الأرض بعيدا عن الوحلدة وانحلدارة لأسفل & \\
\hline$\%$ \% & 0 & 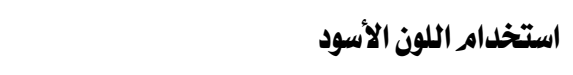 & \\
\hline$\% r r, r$ & $r$ & رسم خط الأرض بعيلا عن الوحدة وانحلارة لأسفل & رسم الشخص \\
\hline$\%$ \% r,o & 0 & استخدام اللون الأسود اس & \\
\hline$\% 17,4$ & 1 & رسم الأسرة داخل إطار & 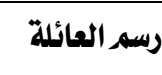 \\
\hline$\% r r, \xi$ & r & رسم الحالة لنفسها وهى بعيدة عن أفراد الأسرة & \\
\hline$\% r r, \xi$ & r & رسم خط الأرض بعيلا عن الوحدة وانحدارة لأسفل & \\
\hline$\%$ \% & ० & استخداه اللون الأسود & \\
\hline
\end{tabular}

يتضــح مـن جـدول ( () أن المؤشـرات الدالـة علـى العزلــة الاجتماعيـة فـى الرسـوم

المقيـدة هـى : رســم البـاب مغلـق، رسـم البـاب عليـة قفـل ،ورسـم النوافـذ مغلقــة ،ورسـم

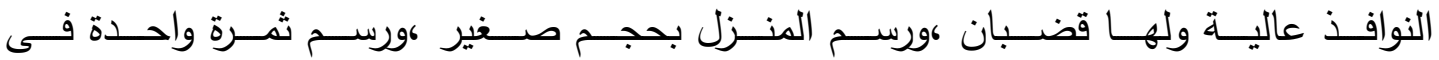
الشجرة،ورسـم صـائر وحيـد يعـيش فـوق الثـجرة ،ورسـم الأسـرة داخـل إطــار يشـبه المنـزل ورسـم الحالـة لنفسـها بعيـدة عـن أفـراد الأســرة ،ورسـم خـط الأرض بعيـدا عـن الوحـدات وانحدارة إلى أسفل، واستخدام اللون الأسود بكثرة. 
المבد (117) أكتوبر ج(0) r.1^r

مجلة كلية التربية ببنها

الحالة الأولى : جلدول رقم ( ( المعالجة الاحصائية للمؤشرات الدالـة لتشخيص العزلـة الاجتماعيـة (ذ = )

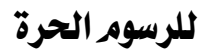

\begin{tabular}{|c|c|c|c|}
\hline النسبة المئوية & التكرار & المؤشرات & المقياس \\
\hline$\% 1$. & 1 & رسم شخص يقف بمفردة & الرسوه الحرة \\
\hline$\% 1 \cdots$ & 1 & رسم شجرة بها تثاحة واحلة & (رسم خطر على بالك الأز -ورسم حلث هاه) \\
\hline
\end{tabular}

يتضـح من جدول (Y) أن المؤشـرات الدالـة على العزلـة الاجتماعيـة فى الرسـوم الحرة

هى: رسم شخص يقف بمفردة ،ورسم شجرة بها تفاحة واحدة

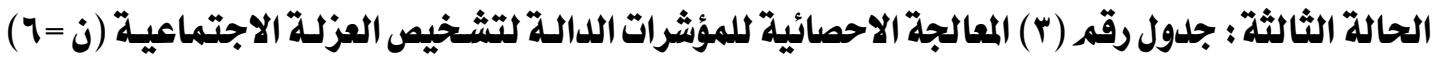
للرسوه الحرة

\begin{tabular}{|c|c|c|c|}
\hline النسبة المئوية & التكرار & المؤشرات & المقياس \\
\hline$\% 1 \cdots$ & 1 & رسم بحر وبله سمكة واحلدة & (رسم خطر على بالك الأز - الحرسه حلىث هاه ) \\
\hline
\end{tabular}

يتضح من جدول (ب) أن المؤشرات الدالة على العزلة الاجتماعية فى الرسوم الحرة هى

$$
\text { : رسم بحر كبير وبـه سمكة واحدة }
$$

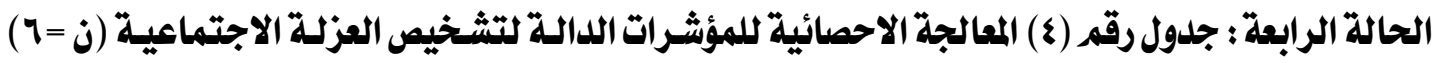

للاسوهر الحرة

\begin{tabular}{|c|c|c|c|}
\hline النسبة المئوية & التكرار & المؤشرات & المقياس \\
\hline$\% 1 \%$ & 1 & رسمر بنت صفيرة الحجم & (رسم خطر على بالك الأز - الروسم حلدث هام ) \\
\hline
\end{tabular}

يتضح من جدول (ع) أن المؤشرات الدالة على العزلة الاجتماعية فى الرسوم الحرة هى

$$
\text { :رسم بنت صغيرة الحجم تقف بمفردها: }
$$

الحالة الخامسة : جلدول رقم (0) المعالجة الاحصائية للمؤشرات الدالة لتشخيص العزلة الاجتماعيـة (ذ =7 )

\begin{tabular}{|c|c|c|c|}
\hline النسبة المئوية & التكرار & المؤشرات & المقياس \\
\hline$\% 1 \ldots$ & 1 & 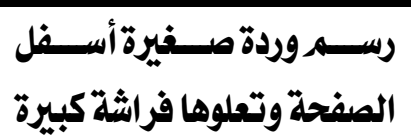 & (رسمر خطر على بالك الأز - الروسم حلدث هام ) \\
\hline
\end{tabular}

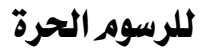


يتضح من جدول (0) أن المؤشرات الدالة على العزلة الاجتماعية فى الرسوم الحرة هى : رسم وردة صغيرة أسفل الصفحة وتعلوها فراشة كبيرة

الحالة السادسة : جلول رقم (7) المعالجة الاحصائية للمؤشرات الدالة لتشخيص العزلة الاجتماعية (ذ = ج ) للرسوه الحرة

\begin{tabular}{|c|c|c|c|}
\hline النسبة المئوية & التكرار & المؤشرات & المقياس \\
\hline$\% 1$. & 1 & رسم سمكة واحلدة كبيرة & (رسهم خطر على بالك الأز - ورسم حلث هام ) \\
\hline
\end{tabular}

يتضـح من جدول (7) أن المؤشرات الدالـة على العزلـة الاجتماعيـة فى الرسـوم الحرة هى: رسم سمكة واحدة كبيرة الحجم فى البحر 


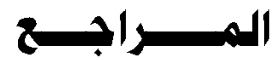

أميمـة متولى جبر (1 . . ب) استخدام رسوم الأطفال فى الكشف عن ديناميات شخصية

الأطفال المساء معاملتهم، رسالة ماجستير غير منشورة، كلية التربية، جامعة الزقازيق التئي

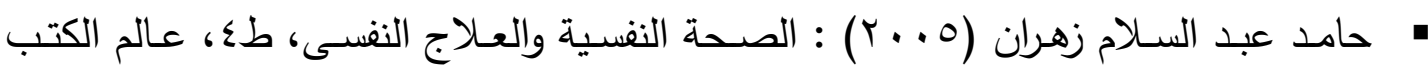

$$
\text { للنشر والتوزيع }
$$

خميس عبد الرحمن رداد (9 . . r) : المؤشرات البيئية كجزء من مؤشرات التتمية المستدامة،

ورقة عمل مقدمة فى المؤتمر الإحصائى العربى الثانى، سرت، ليبيا زكريا الثربينى ( ( . ب) : الإحصاء الابارامترى فى العلوم النفسية والتزبويـة والاجتماعية، القاهرة، مكتبة الأنجلو المصرية

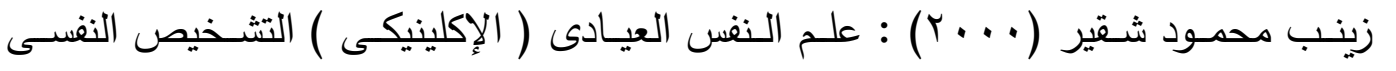
والارشاد النفسى، القاهرة، د.ن سـامية القطان (9V9 ( ) : كيف تقوم بالدراسـة الكلينيكيـة، مكتبـة الانجلو المصرية، ج) ،

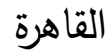
سامية محمد صابر (1991) : فاعلية استخدام الرسم الاسقاطى فى الكثف عن ديناميات الثخصية، رسالة دكتوراة غير منشورة، كلية التربية ببنها، جامعة الزقازيق

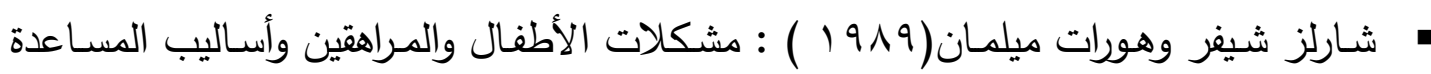
فيها، ترجمة نسيمة داود ونزية حمدى، منشورات الجامعة الأردنية • صفوت أرنست فرج (71911) : الذكاء ورسوم الأطفال، القاهرة، دار الثقافة • صفوت أرنست فرج (r99 199 ) : الذكاء ورسوم الأطفال، القاهرة، دار الثقافة

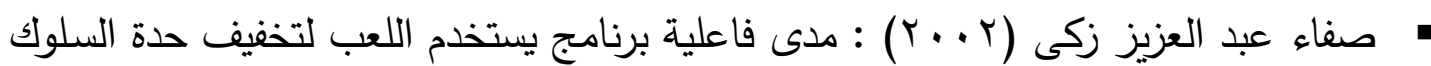
الانطوائى لدى ضعاف السمع، رسالة ماجستير غير منشورة، معهد الدراسات العليا للطفولة، جامعة عين شمس • عـادل كمـال خضـر (991 ()): رسـوم الاطفـال لشكل الانسـان ودلالتهـا النفسـية، الهيئـة

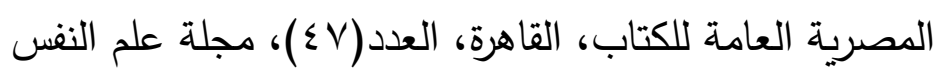




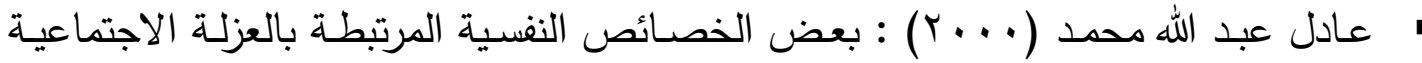

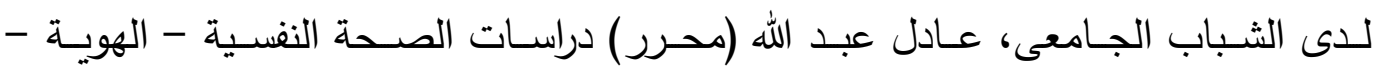
الاغتراب - الاضطرابات النفسية، القاهرة، دار الارشاد

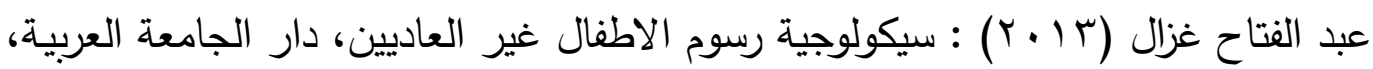

$$
\text { الاسكندرية }
$$

" عبد المطلب القريطى (990) ) : مدخل الـى سيكولوجية رسوم الاطفال، دار المعارف،

مصر

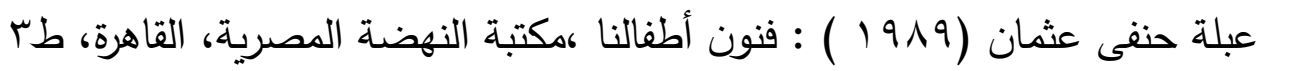

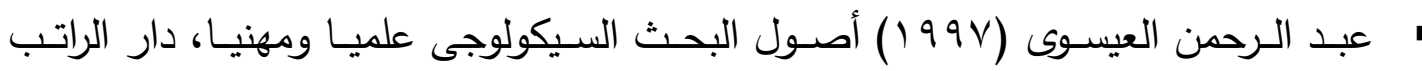

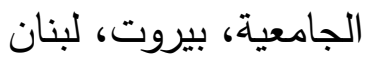
• على الجلبى (9>1 ( ) ) : الطب النفسى الاجتماعى ( النظريـة والتطبيق )، دائرة المعارف

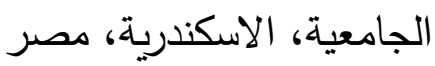

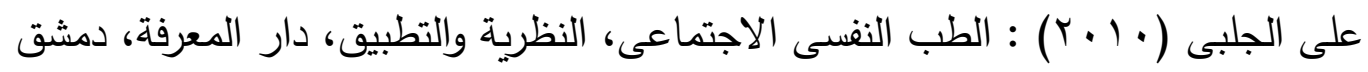

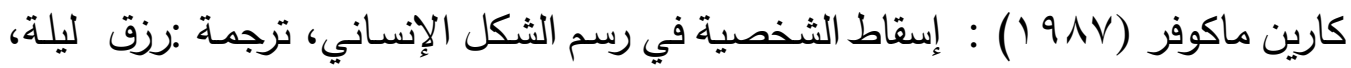
دار النهضة العربية، بيروت كمال محمد دسوقى (9111) : ذخيرة علوم النفس، المجلد الأول، القاهرة، الدار الدولية للنشر لندا هارجروف، جيمس بوتيت (911 (1) : التقييم فى التربية الخاصة ( ترجمة عبد العزيز السرطاوى وزيدان السرطاوى ) الرياض، مكتبة الصفحات الذهبية لويس كامل مليكة ( •999 (19): دراسة الثخصية عن طريق الرسم، الكويت ،دارالقلم

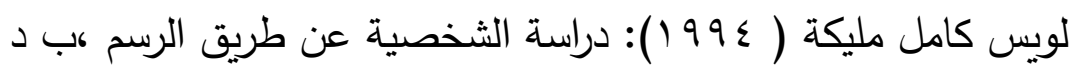

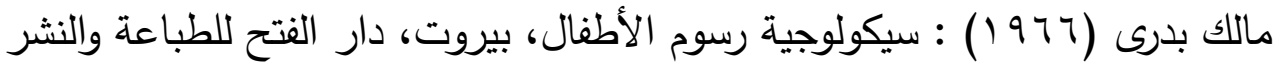

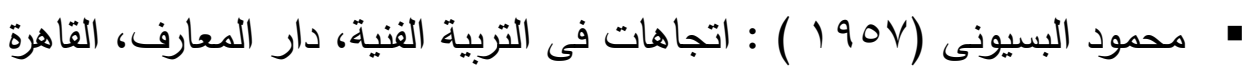

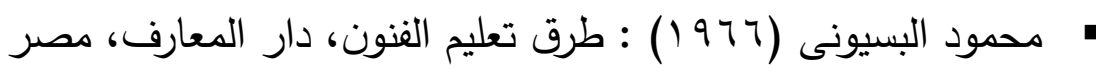

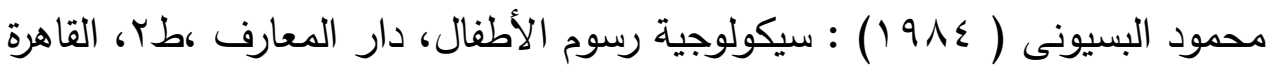

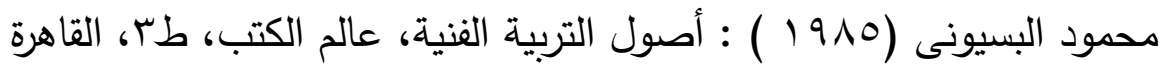




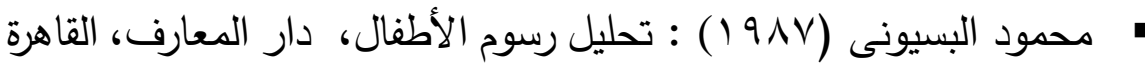

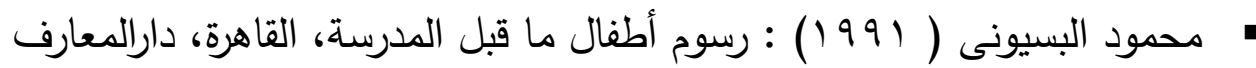

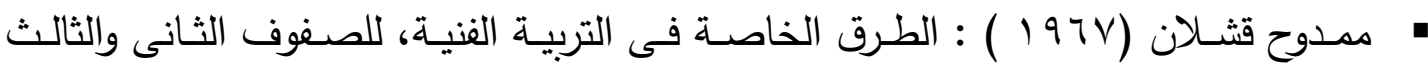

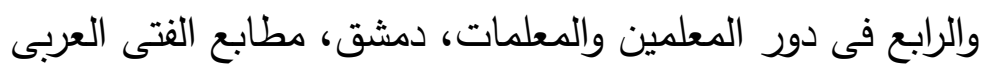

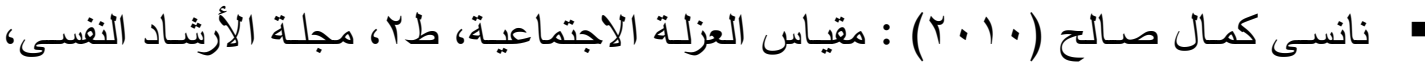

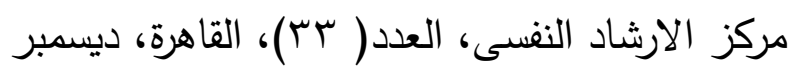

- Auxter, D. (1971). Learning disabilities among deaf populations.

- Exceptional Children. 37(81.573-577.

- Bennett,verginia.(1966) : Combinations of figure drawing characteristics related to the drawer is self concept, Journal of projective techniques, personality Assessment,v.30,N.2,pp.192- 196

- Davis , c.Hooper,J. (1975) :Comparison of (H.T.P) drawing of young deaf and hearing children.journal of personality assessment, Vol 39 ,I, $28-33$

- Bunch, G. O. \& Melnyk, T. L. (1989). A review of the evidence for a learning-disabled hearing-impaired sub-group. American Annals of the Deaf. 134(51. 297-300.

- Gondor, Emery.(1954): Art And Play Therapy, Doubleday \&

- Company, Inc, New York

- Harris, D.B.(1963): Children Drawings as Measures of Intellectual

- Maturity: A Revision and Extension of the Goodenough Draw-a-Man

- Test. N.Y.: Harcourt, Brace and world Inc.

- Hammer,E .(1960) : The house tree person ( H.P.T ) Drawing as projective technique with children in : projective technique with children. Edited by rabin and Haworth,m.r grune,stration inc . New York

- Klepsh,m.Logie,L.(1982) : Children draw and tell an introduction to the projective uses of children is HFD . New York : Brunner, mazel publishers

- Kelberman paula,may.(1988) : Observation drawing :A comparative study of two sensory - based instruclionsal approaches, EducationArt vol 149-06 A

- Krywko,Krystyann,EDD.(2014): learning disabilities \&Hearing loss , Volta Voices; Mar,Apr;21,2;Proquest Nursing\&Allied Health Source 
- Kretschmer, R., \& Kretschmer, L. (1978). Language development and intervention with hearing impaired Baltimore, MD: University Park Press.

- Laughton, J. (1989). The learning disabled, hearing impaired student:Reality, myth, or overextension? Topics in Language Disorders.

- 9(41. 70-79.

- Mauk,G.,\&Mauk,P.(1993). Compounding the challenge: Young deaf children and learing disabilities. Perspectives, 12(2),12-18

- Morgan,A.,\&Vernon,M.(1994):Aguide to the diagnosis of learning disabilities in deaf and hard of hearing children and adults ,American Annals of the deaf,139(3),358-369

- Pallack, B.(1997): Educating children who are deaf or hard of hearing :Additional learing problems .Reston, VA:Eric clearing house on disabilities and gifted education . Eric document reproduction service No. ed\# 414666

- Plapinger, D. \& Sikora, D. (1990). Diagnosing a learning disability in ahearing-impaired child. American Annuals of the Deaf. 135(41. 285-292

- Powers, A. Elliott, R. \& Funderburg, R. (1987). Learning disabled hearing impaired students: Are they being identified? The Volta Review. 89121.99-105.

- Röhrle, B., (2008) Aufgaben und Hintergruende In Röhrle, B., Caspar, F. \& Schlottke, P.F. (Hrsg.) (2008). Lehrbuch der klinischpsychologischen Diagnostik. 13-29.

- Samar,V.J., Parasnis,I.,\&Berent,G.P.(1998): learning disabilities, attention deficit disorders, and deafness. In M.marschark\&M.D clark(Eds), psychological perspectives on deafness(pp.199242).mahwah,NJ:Erlbaum

- Soukup,M.,\&Feinstein,S.(2007). Identification, assessment,and intervention strategies for deaf and hard of hearing students with learning disabilities. American Annals of the deaf, 152(1),56-62. Retrieved from Proquest Education Journals

- Van Vuuren,E.(1995,July): The deaf pupil with learning disabilities . paper presented at the International congress on education of the deaf, tel aviv, Israel. (ERIC Document Reproduction service no. ED392177) 